\title{
Structural, genetic, and serological elucidation of Streptococcus pneumoniae serogroup 24 serotypes: Discovery of a new serotype, $24 C$, with a variable capsule structure
}

Ganaie, Feroze; Maruhn, Karsten; Li, Chengxin; Porambo, Richard J; Elverdal, Pernille L.; Abeygunwardana, Chitrananda; van der Linden, Mark; Duus, Jens Øilgaard; Sheppard, Carmen L; Nahm, Moon $\mathrm{H}$

Published in:

Journal of Clinical Microbiology

Link to article, DOI:

10.1128/JCM.00540-21

Publication date:

2021

Document Version

Peer reviewed version

Link back to DTU Orbit

Citation (APA):

Ganaie, F., Maruhn, K., Li, C., Porambo, R. J., Elverdal, P. L., Abeygunwardana, C., van der Linden, M., Duus, J. Ø., Sheppard, C. L., \& Nahm, M. H. (2021). Structural, genetic, and serological elucidation of Streptococcus pneumoniae serogroup 24 serotypes: Discovery of a new serotype, $24 \mathrm{C}$, with a variable capsule structure. Journal of Clinical Microbiology, 59(7), [e00540-21]. https://doi.org/10.1128/JCM.00540-21

\section{General rights}

Copyright and moral rights for the publications made accessible in the public portal are retained by the authors and/or other copyright owners and it is a condition of accessing publications that users recognise and abide by the legal requirements associated with these rights.

- Users may download and print one copy of any publication from the public portal for the purpose of private study or research.

- You may not further distribute the material or use it for any profit-making activity or commercial gain

- You may freely distribute the URL identifying the publication in the public portal 
Copyright $\odot 2021$ American Society for Microbiology. All Rights Reserved.

1 Structural, genetic, and serological elucidation of Streptococcus pneumoniae

2 serogroup 24 serotypes: Discovery of a new serotype, $24 \mathrm{C}$, with a variable capsule

3 structure

4 Feroze Ganaie, ${ }^{a,{ }^{*}}$ Karsten Maruhn, ${ }^{\mathrm{b},{ }^{*}}$ Chengxin Li, ${ }^{\mathrm{c},{ }^{*}}$ Richard J. Porambo, ${ }^{\mathrm{d}}$ Pernille L.

5 Elverdal, ${ }^{\mathrm{e}}$ Chitrananda Abeygunwardana, ${ }^{\mathrm{d}}$ Mark van der Linden, ${ }^{\mathrm{b}}$ Jens $\varnothing$. Duus, ${ }^{\mathrm{c}}$ Carmen

6 L. Sheppard, ${ }^{\mathrm{f}}$ Moon H. Nahm ${ }^{\mathrm{a}, \#}$

7 aDepartment of Medicine, University of Alabama at Birmingham, Birmingham, Alabama,

8 USA

9 bNational Reference Center for Streptococci, University Hospital RWTH, Aachen,

10 Germany

11 'Department of Chemistry, Technical University of Denmark, Kgs. Lyngby, Denmark

12 dMerck \& Co., Inc., West Point, PA, USA

13 eSSI Diagnostica A/S, Research \& Development, Hillerød, Denmark

14 'Vaccine Preventable Bacteria Section, Public Health England-National Infection Service,

15 Colindale, London, UK

16 Running Head: Discovery of a novel pneumococcal capsule type (24C)

${ }^{\#}$ Address correspondence to Moon H. Nahm, mnahm@uabmc.edu

*These authors contributed equally to this work. The author order was determined by the agreement among the heads of the laboratories of the co-first authors. 


\section{ABSTRACT}

Pneumococcal capsules are important in pneumococcal pathogenesis and vaccine development. Though conjugate vaccines have brought about a significant reduction in invasive pneumococcal disease (IPD) caused by vaccine serotypes, the relative serotype prevalence has shifted with dramatic emergence of serotype $24 \mathrm{~F}$ in some countries. Herein, we describe fourteen isolates (thirteen IPD and one non-IPD) expressing a new capsule type, $24 \mathrm{C}$, which resembles $24 \mathrm{~F}$ but has a novel serological profile. We also describe the antigenic, biochemical, and genetic bases of $24 \mathrm{~F}$ and $24 \mathrm{C}$ and the related serotypes $24 \mathrm{~A}$ and $24 \mathrm{~B}$. Structural studies show that $24 \mathrm{~B}, 24 \mathrm{C}$, and $24 \mathrm{~F}$ have identical polysaccharide backbones $[\beta-\operatorname{Rib} f-(1 \rightarrow 4)-\alpha-R h a p-(1 \rightarrow 3)-\beta-G l c p N A c-(1 \rightarrow 4)-\beta-R h a p-$ $(1 \rightarrow 4)-\beta-G \mid c p]$ but with different side chains: 24F has arabinitol-phosphate, and 24B has ribitol-phosphate. $24 \mathrm{C}$ has a mixture of $24 \mathrm{~F}$ and $24 \mathrm{~B}$ repeating units, with ratio of ribitol to arabinitol being strain-dependent. In contrast, 24A capsule has a backbone without $\beta$-Ribf but with arabinitol-phosphate and phosphocholine side chains. These structures indicate that factor-sera $24 d$ and 24 e respectively recognize arabinitol and ribitol, which explains the serology of serogroup 24 , including those of $24 \mathrm{C}$. The structures can be genetically described by the bi-specificity of $w c x G$, capable of transferring arabinitol or ribitol when arabinitol is limiting. Arabinitol is likely not produced in 24B but is produced in reduced amounts in $24 \mathrm{C}$ due to various mutations in $a b p A$ or $a b p B$ genes. Our findings demonstrate how pneumococci modulate their capsule structure and immunologic properties with small genetic changes, thereby evading host immune responses. Our findings also suggest a potential for new capsule types within serogroup 24 . 


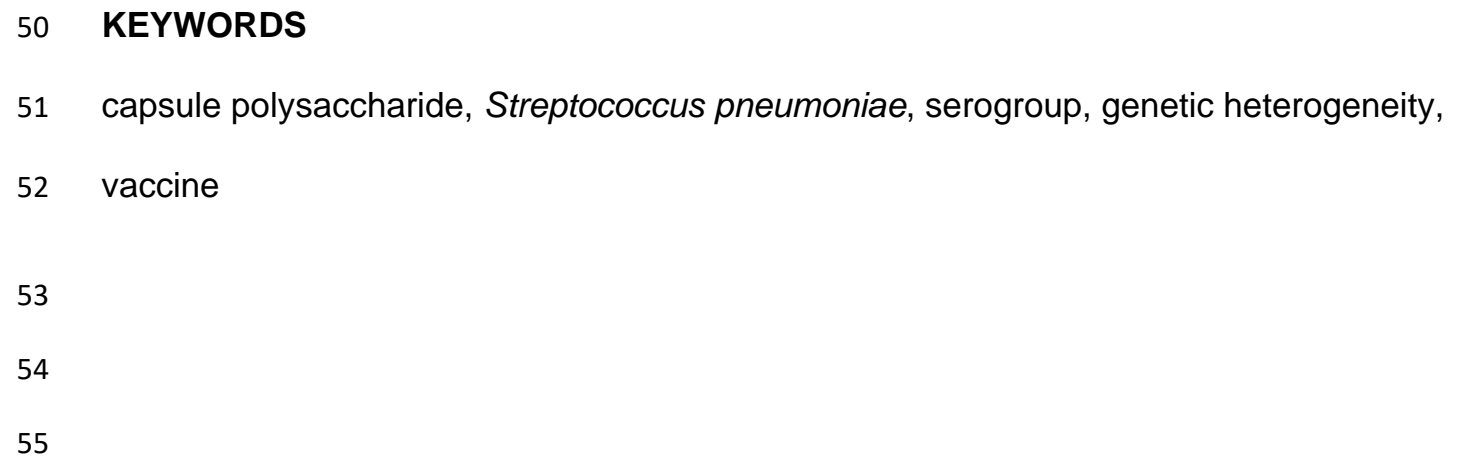




\section{INTRODUCTION}

A broad range of bacterial species have polysaccharides (PSs) on their surface, covering the bacterial cell wall and/or other critical surface structures, thereby shielding the bacteria from the host immune system $(1,2)$. The surface PS structures, which include the bacterial capsule and lipopolysaccharide (LPS), are important virulence factors since they hide other structures and become the primary targets of the host immune system. Antibodies against them are highly protective (3), but the antibody protection is generally serotype-specific, with bacterial species being able to co-exist with their hosts because they produce diverse types of surface PSs (4). Consequently, understanding the structural and genetic bases for their diversity is essential in designing diagnostic methods, vaccines, and other therapeutic measures against bacteria $(2,5)$.

A good example is Streptococcus pneumoniae (the pneumococcus). The pneumococcus can display more than 100 biochemically and antigenically unique capsule types $(6,7)$. The capsule is an essential virulence factor since acapsular pneumococcus rarely causes invasive pneumococcal disease (IPD) (8). Pneumococci produce capsule in large amounts. Indeed, the detection of capsular PSs in urine is used to diagnose nonbacteremic pneumonia (9). Antibodies to the capsule can efficiently, but in a serotypespecific manner, opsonize pneumococcus for phagocytes. Consequently, mixtures of pneumococcal capsules have been used as vaccines (10). Recent introductions of pneumococcal conjugate vaccines (PCVs) containing 7, 10, or 13 different capsule types have significantly reduced the IPD burden caused by vaccine serotypes (11). However, IPD caused by nonvaccine serotypes (NVTs) has progressively increased over time (12). Thus, to monitor the efficacy of the current vaccines, it is critical to monitor the emergence of NVTs and the appearance of novel capsule types. Hence, it is crucial to understand the 
genetic and chemical bases of the capsule PSs of pneumococci expressing NVTs or potential novel serotypes.

One of the prominent NVTs that has emerged in recent years is serotype $24 \mathrm{~F}$, which is especially common among antibiotic-resistant IPD cases (13). Following the introduction of PCV13, there has been an upsurge of serotype 24F as the cause of IPD in many countries (14-16); although, no substantial increase has been observed in the USA $(17,18)$. In Japan, serotype 24F has increased remarkably since 2012 (3.1\% in pre PCV13 period and $22.2 \%$ in post PCV13 period) $(19,20)$. Based on the data from several European countries like Germany $(1.5 \%$ in pre PCV13 period and $13.4 \%$ in post PCV13 period), serotype $24 \mathrm{~F}$ has been reported as the most significantly increasing non-PCV13 serotype in children $<5$ years of age $(21,22)$. In a recent time-series analysis from France, the emergent serotype $24 \mathrm{~F}$ was reported as the leading cause of pediatric meningitis (18\% in the early PCV13 period and $74 \%$ in late PCV13 period) $(23,24)$. Similarly, United Kingdom (7.4\%) and Denmark (14.7\%) have reported an increase of IPD due to serotype 24F since 2012 (25-28). Yet, the chemical structures of serotype $24 \mathrm{~F}$ as well as of two related serotypes (24A and 24B) have remained unknown. Further, during IPD surveillance, we discovered several pneumococcal isolates belonging to serogroup 24 but displaying a novel serological profile. Herein, we elucidate the chemical and genetic bases for a novel serotype (named 24C) in addition to determining the capsule structures of the related serotypes $24 \mathrm{~F}, 24 \mathrm{~B}$, and $24 \mathrm{~A}$.

\section{Results}

Serotype $24 \mathrm{C}(24 X)$ has serological properties of serotypes $24 \mathrm{~F}$ and $24 \mathrm{~B}$ 
Serogroup 24 contains three established serotypes (24A, 24B, and 24F) with unique serologic properties. While all the three serotypes react with Pool C antiserum (Table 1), only serotype $24 \mathrm{~A}$ reacts with factor serum (FS) $24 \mathrm{c}$. Serotypes $24 \mathrm{~F}$ and $24 \mathrm{~B}$ can be distinguished from each other because serotype $24 \mathrm{~F}$ reacts only with FS24d, and serotype $24 \mathrm{~B}$ reacts only with FS24e. Recently, pneumococcal strains with atypical serologic properties of serogroup 24 were found in multiple countries. These atypical strains (MNY585-MNY591, and PHE194136) agglutinated with pool C antiserum but not with factor serum $24 \mathrm{c}$, indicating that the strains belong to serogroup 24 but are not serotype $24 \mathrm{~A}$. However, unlike serotypes $24 \mathrm{~B}$ and $24 \mathrm{~F}$, the atypical strains agglutinated with both FS24d and FS24e (Table 1). These serologically unique strains were provisionally labeled as serotype "24X."

\section{Genetic characterization of serotype 24X}

To investigate the genetic basis of serotype $24 X$, the cps loci of seven $24 X$ strains (MNY585-MNY591), three 24F strains (MNY576-MNY578), three 24B strains (MNY582-MNY584), and three 24A strains (MNY579-MNY581) were determined by whole-genome sequencing. All the sequences are available (GenBank accession numbers: MW683289-304). The cps locus from a representative 24X strain (MNY586) was compared with the published sequences of serotypes 24F, 24B, and 24A (Fig. 1A). The cps locus of MNY586 is $~ 23 k b$ long, flanked upstream by the dexB and downstream by the aliA gene, is syntenic, and is $94 \%$ identical to the cps loci of $24 \mathrm{~F}$ and $24 \mathrm{~B}$. Like the cps loci of 24F and 24B, the MNY586 cps locus has three open reading frames ( $r b s F$, $w z y_{s}$, and $w c x K_{s}$ ) that are absent in the $24 \mathrm{~A} c p s$ locus. $r b s F$ is a ribofuranose (Ribf) biosynthetic gene. $w z y_{s}$ and $w c x K_{s}$ were so named because they are fragments of 
complete wzy and wcxK genes. The two genetic fragments are likely nonfunctional as $24 \mathrm{X}$ cps has another intact wzy gene, and $w c x K_{s}$ is much shorter than the wcxK gene of $24 \mathrm{~A}$ (561 bp vs $843 \mathrm{bp}$ ). Further, the wzx flippase gene of $24 \mathrm{X}$ is almost $100 \%$ identical to that of $24 \mathrm{~F}$ and $24 \mathrm{~B}$ but shares only $48 \%$ nucleotide identity with the flippase of $24 \mathrm{~A}$. These results indicate that $24 \mathrm{X}$ is genetically similar to $24 \mathrm{~F}$ and $24 \mathrm{~B}$ but not to $24 \mathrm{~A}$.

When the cps loci of several 24F (MNY576-MNY578) and 24B (MNY582-MNY584) strains from Germany were compared with the published sequences of 24F (CR931688) and 24B (CR931687), certain differences were identified among 24B cps sequences. The German 24B strains included a pseudo glf gene, which was previously reported only in serotypes $24 \mathrm{~F}$ and $24 \mathrm{~A} \operatorname{cps}(29,30)$. More significantly, the previously reported mutations in the $a b p A$ (formerly known as abp1, a putative nucleotidyltransferase involved in the biosynthesis of CDP-arabinitol ) (31) and $r m / C$ genes of 24B (29) were not identified in the three 24B strains (MNY582-MNY584) (Fig. 1A). The absence of the frameshift mutation of $a b p A$ in 24B strains was problematic since the frameshift was reported to be the genetic basis for distinguishing serotypes $24 \mathrm{~F}$ and 24B (29).

Therefore, we re-investigated the sequence of a $\sim 2.6 \mathrm{~kb}$ region including $w c x G$, $a b p A$, and $a b p B$ (formerly known as $a b p 2$ ) (31) genes of several strains representing the four related serotypes, namely, serotype 24X (MNY585, MNY586, and MNY589), serotype 24F (MNY576), serotype 24B (MNY583), and serotype 24A (MNY580) by the Sanger sequencing method (GenBank accession numbers: MW447149-154). Both sequencing approaches (whole genome and Sanger) produced identical results. WcxG and $\mathrm{AbpB}$ (amino acid) sequences of serotypes $24 \mathrm{X}, 24 \mathrm{~F}, 24 \mathrm{~B}$, and $24 \mathrm{~A}$ were largely identical to the published sequences and revealed no serotype-specific differences (Fig. 
S1). An exception was that one $24 \mathrm{X}$ strain (MNY585) showed a single amino acid substitution: T188I in the AbpB protein (Fig. S1). When AbpA (amino acid) sequences were examined (Fig. 1B), 24A and 24F sequences were identical except for the $\mathrm{F} 77 \mathrm{~L}$ amino acid change in CR931688. When the 24B AbpA sequences were examined, the German strains did not show the frameshift mutations described previously (29). Instead, they contained non-synonymous substitutions with amino acid changes: D222Y for strain MNY583 and G78W for strains MNY582 and MNY584. These exchanges respectively disrupt the DxD and GGxxG motifs that are considered to be important in the AbpA enzyme function (31) and would render the AbpA inactive for the 24B strains. When abpA sequences of $24 \mathrm{X}$ strains were examined, two strains (MNY586 and MNY589) encoded proteins that were two amino acids shorter and twelve amino acids longer, respectively (Fig. 1B). The C-terminal changes may affect the AbpA enzyme function. Intriguingly, one 24X strain (MNY585) had an abpA sequence identical to a 24F strain (MNY576) and to all 24A strains. Thus, MNY585, which has a mutated AbpB, is likely to express fully functional AbpA.

Since the above studies indicate that the genetic bases for $24 \mathrm{X}$ and $24 \mathrm{~B}$ are heterogeneous, we further investigated if the novel serological properties of $24 \mathrm{X}$ could be attributed to the genes within or outside the cps locus. We created isogenic variants by transferring the full cps loci of 24X (MNY586 and MNY585), 24F (MNY576), 24B (MNY583), and 24A (MNY580) into an unencapsulated TIGR4 genetic background (TIGR-JS). The newly created isogenic strains expressed the serological profile of the cps donor (Table 3). Thus, the unique antigenic properties of serotype $24 \mathrm{X}$ and of the related serotypes are controlled by the genes residing within their respective cps loci. 


\section{Structural characterization of $24 \mathrm{C}, 24 \mathrm{~F}, 24 \mathrm{~B}$, and $24 \mathrm{~A}$ capsule polysaccharides}

Although serotypes $24 \mathrm{~F}, 24 \mathrm{~B}$, and $24 \mathrm{~A}$ have been defined serologically for a long time, the biochemical structures of their capsular polysaccharide have been unknown. To identify the biochemical basis for the novel immunologic properties of serotype $24 X$, we compared one-dimensional (1D) ${ }^{1} \mathrm{H}$ NMR spectra of the capsular PSs from serotypes 24X, 24F, and 24B. Capsular PSs were purified from a single colony of $24 \mathrm{X}$ strains (MNY585, MNY586, MNY589, and the PHE194136), 24F strain (24F/2), and 24B strain (24B/2), and their ${ }^{1} \mathrm{H}$ NMR spectra of the selected region (chemical shifts of 3.6 to 4.0 ppm) were examined (Fig. 2A). This spectral region, which corresponds to the sugar/polyalcohol region, is unique for each serotype. Thus, despite high similarities in their cps loci, all three serotypes (24F, 24B, and 24X) produce chemically different capsular PSs. Therefore, the provisional name $24 \mathrm{X}$ was replaced with a new name, $24 \mathrm{C}$, making it the fourth serotype within serogroup 24.

To fully determine the repeating unit structures, the purified capsule PSs of serotypes $24 \mathrm{~B}, 24 \mathrm{~F}$, and $24 \mathrm{C}$ were examined with standard two-dimensional (2D) NMR techniques. Their chemical shifts assignments are listed in Table 2. All the capsular PSs have an identical five residue backbone $[\beta-\operatorname{Ribf}-(1 \rightarrow 4)-\alpha-$ Rhap-( $(1 \rightarrow 3)-\beta-G l c p N A c-(1 \rightarrow 4)-$ $\beta$-Rhap- $(1 \rightarrow 4)-\beta-$ Glcp], labeled A through $E$ in Table 2 and Fig. S2, but each has different side chains attached to $\beta$-Rhap. When the heteronuclear single quantum coherence (HSQC) spectrum was studied, the 24F repeating unit was found to have arabinitol attached to $\beta$-Rhap, whereas 24B has ribitol. Though arabinitol and ribitol are stereoisomers, they form different spin systems, as indicated in Table 2. Interestingly, 24C spectra showed both arabinitol (labeled F1) and ribitol (labeled F2), indicating that the $24 \mathrm{C}$ repeating units are a mixture of $24 \mathrm{~F}$ and $24 \mathrm{~B}$ (Fig. $3 \mathrm{~A}$ and $3 \mathrm{~B}$ ). 
The presence of both ribitol and arabinitol in 24C PS was also confirmed with ${ }^{31} \mathrm{P}$ and ${ }^{1} \mathrm{H}^{3}{ }^{31} \mathrm{P}$ HMBC spectra (Fig. $\left.3 \mathrm{C}\right)$. The spectra revealed one phosphate $\left(\mathrm{PO}_{4}\right)$ group in serotype 24B linked between the first carbon of ribitol and the third carbon of $\beta$-Rhap. Similarly, $24 \mathrm{C}$ capsule PS showed two $\mathrm{PO}_{4}$ groups, one each linked to the first carbon of ribitol ( $\left.\mathrm{PO}_{4}-1-\mathrm{Ribitol}\right)$ and the first carbon of arabinitol $\left(\mathrm{PO}_{4}-1-\right.$ Arabinitol). The complete repeating unit structures of $24 \mathrm{C}, 24 \mathrm{~B}$, and $24 \mathrm{~F}$ are depicted in Fig. 4 . The structure also indicates that the antigens of serological markers FS24d or FS24e are primarily determined by arabinitol and ribitol, respectively.

While we investigated 24C capsular PS structures from many strains, we noticed that the capsule PSs from different $24 \mathrm{C}$ strains had variable mixtures of $24 \mathrm{~B}$ and $24 \mathrm{~F}$ repeating units, i.e., ribitol and arabinitol. For instance, the ratio of ribitol to arabinitol was 1:1 for MNY586, but the ratio was 1:1.5 and 1:2.3 for two other $24 \mathrm{C}$ strains from Germany (MNY585 and MNY589) (Fig. 2A) and 1:3.5 for the English strain (PHE194136). This strain-to-strain variability in the composition was confirmed by monosaccharide composition analysis.

Following the determination of the $24 \mathrm{~F}, 24 \mathrm{~B}$, and $24 \mathrm{C}$ capsule PS structures, the structure of $24 \mathrm{~A}$ capsule PS purified from the $24 \mathrm{~A} / 2$ strain was elucidated. HSQC spectra analysis showed the repeating unit of serotype $24 \mathrm{~A}$ to be: $\rightarrow 4)-[-\alpha-\operatorname{Rhap}-(1 \rightarrow 3)]-\beta-$ GlcpNAc-[6-P-Cho]-(1 $\rightarrow 4)-\beta-R h a p-[3-P-1-A r a b i n i t o l]-(1 \rightarrow 4)-\beta-G l c p-(1 \rightarrow$ (Fig. 4). 24A PS has P-Cho attached to the sixth carbon of the GlcpNAc and $\mathrm{PO}_{4}-1$-arabinitol attached to the third carbon of $\beta$-Rhap. The absence of Ribf was consistent with the ${ }^{1} \mathrm{H}$ NMR spectra of $24 \mathrm{~A}$, which did not show the Ribf-specific anomeric peak at $5.3 \mathrm{ppm}$ (Fig. 2B). Further, the attachments of $\mathrm{P}$-Cho and $\mathrm{PO}_{4}-1$-arabinitol were confirmed with ${ }^{31} \mathrm{P}$ and ${ }^{1} \mathrm{H}^{-31} \mathrm{P}$ HMBC spectra (Fig. S3). 


\section{Identifying the genetic bases for 24C, 24F, 24B, and 24A PS structures}

Once the PS structures were determined for serotypes $24 \mathrm{C}, 24 \mathrm{~F}, 24 \mathrm{~B}$, and $24 \mathrm{~A}$, the role of each cps gene could be determined. All the cps loci have wchA as an initial glycosyltransferase (GT), which would add glucose ( $\beta-\mathrm{D}-\mathrm{Glc} p)$ to the lipid carrier. The $\beta$-LRhap- $(1 \rightarrow 4)-\beta-D-G l c p$ linkage should be formed by $w c h F$, which is known to catalyze this linkage (32). There are two more GTs (wcxJ and $w c x l$ ), which are unique to serogroup 24 and whose functions had been unknown (32). To better understand their biosynthetic role, we performed phylogenetic analyses for the genes with the homologs from other serotypes (Fig. S4). wCXJ clustered with GT genes that are primarily involved in GlcNAc or GaINAc transfer (such as, wchL, wcrM, whaK, and wciF); hence, wcxJ was predicted to catalyze the $\beta$-D-GlcpNAc- $(1 \rightarrow 4)-\beta$-L-Rhap linkage. Similarly, the $w c x /$ gene clustered with rhamnosyl transferase genes (such as, wchG, wcxS, wchQ, and wciP) and was thus predicted to catalyze the transfer of $\alpha-$ Rhap to the $\beta$-GlcpNAc via a $1 \rightarrow 3$ linkage.

Finally, the repeating unit backbones of $24 \mathrm{C}, 24 \mathrm{~F}$, and $24 \mathrm{~B}$ contain $\beta-\operatorname{Rib} f-(1 \rightarrow 4)-$ a-Rhap, which is also found in the capsules of 19B, 19C, 7B, 7C, and 7D (32). For serotypes 19B and 19C, it was proposed that $r b s F$ forms NDP-Ribf and wchR transfers NDP-Ribf to $\alpha$-Rhap with a $(1 \rightarrow 4)$ linkage $(32,33)$. To identify the $w c h R$ analog, two other incomplete genes $\left(w c x K_{s}\right.$ and $\left.w z y_{s}\right)$ were investigated for their functional roles. Two 24C strains (FG206 and FG207) were created without these genes (Fig. 5A), and both produced capsules with HSQC spectra identical to the parental strain. Thus, the $w c x K_{s}$ and $w z y_{s}$ genes are nonfunctional, have no role in capsule synthesis, and are evolutionary relics along with $H G 26 X$ and its adjoining tnp. Furthermore, 7B, 7C, and 7D cps only have $r b s F$, without wchR or its analog (32), suggesting that $r b s F$ alone may be

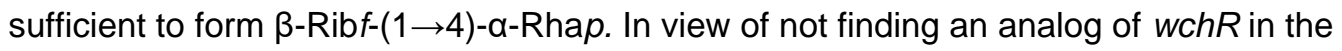


serogroup $24 c p s$, we concluded that, just like in serogroup $7 c p s, r b s F$ is likely sufficient to form $\beta$-Ribf-(1 $\rightarrow 4)-\alpha-$ Rhap in serotypes $24 \mathrm{C}, 24 \mathrm{~F}$ and 24B capsules. Consistent with the biochemical structure, the cps locus of $24 \mathrm{~A}$ does not contain a rbs $F$ gene; thus, no $\beta$ Ribf-(1 $\rightarrow 4)$ linkage is found in the 24A PS repeating unit.

The $c p s$ loci of all serogroup 24 members have wcxG, which belongs to the LicDfamily phosphotransferases (Pfam04991) and was described as adding arabinitol-1- $-\mathrm{PO}_{4}$ to the serotype $17 \mathrm{~F}$ capsule (32). Therefore, for serotypes $24 \mathrm{~F}$ and $24 \mathrm{~A}$, wcx G may transfer arabinitol-1- $\mathrm{PO}_{4}$ that is generated by the products of $a b p A$ and $a b p B$. To explain the ribitol-1- $\mathrm{PO}_{4}$ observed in the structure of serotype 24B, we postulated that $w c x G$ is a bi-specific phosphotransferase and can catalyze the incorporation of ribitol-1- $\mathrm{PO}_{4}$ when arabinitol-1- $\mathrm{PO}_{4}$ is not available. Pneumococci produce ribitol-1- $\mathrm{PO}_{4}$ for teichoic acid synthesis with genes outside of the cps locus. To show that $w c x G$ is responsible for the addition of both ribitol and arabinitol, we a) created a mutant strain, FG205, by deleting wcxG from FG204, which is an isogenic 24C strain derived from MNY586 (Fig. 5A); b) purified its capsule PS; and c) studied the PS with 2D NMR analysis. FG205 PS showed neither arabinitol nor ribitol specific peaks in the HSQC spectra (Fig. 5B). Further, FG205 failed to agglutinate with either FS24d or FS24e (Table 3). Thus, wcxG encodes the bispecific phosphotransferase needed for the biosynthesis of the $24 \mathrm{C}$ capsule PS (i.e., the $w C x G$ gene incorporates both arabinitol-1- $\mathrm{PO}_{4}$ and ribitol-1- $\mathrm{PO}_{4}$ into the repeating unit). The three 24B strains (MNY582-MNY584) did not have the reported frameshift mutation in $a b p A$ but had mutations critical to its function. These mutations would prevent arabinitol-1- $\mathrm{PO}_{4}$ synthesis, thereby permitting $w c x G$ to add ribitol-1- $\mathrm{PO}_{4}$. Two serotype 24C strains (MNY586 and MNY589) have abpA encoded proteins with variable lengths at the C-termini. These alterations may have reduced their ability to produce arabinitol-1- 
$\mathrm{PO}_{4}$ and permitted wcxG to add arabinitol as well as ribitol in different ratios. In the case of MNY585, the AbpA sequence is identical to $24 \mathrm{~F}$ strains, but $\mathrm{AbpB}$, another enzyme necessary for producing arabinitol-1- $\mathrm{PO}_{4}$, has an amino acid substitution (T188I) that may reduce arabinitol-1- $\mathrm{PO}_{4}$, production.

Having assigned all the linkages of serotypes $24 \mathrm{C}, 24 \mathrm{~F}$, and 24B, serotype $24 \mathrm{~A}$ was left with one unassigned linkage and a full-length wcxK gene (LicD-family phosphotransferase, pfam04991). Based on the nature of the linkage and the gene function, wcxK was predicted to catalyze the linkage between P-Cho and $\beta$-GlcpNAc.

\section{Discussion}

Herein, we describe the new capsule type $24 \mathrm{C}$ and identify the chemical structures of the related serotypes $24 \mathrm{~F}, 24 \mathrm{~B}$, and $24 \mathrm{~A}$. Structural analysis showed that $24 \mathrm{~F}$ and $24 \mathrm{~B}$ have the identical five-residue backbones $[\beta-\operatorname{Ribf}-(1 \rightarrow 4)-\alpha-\operatorname{Rhap}-(1 \rightarrow 3)-\beta-\mathrm{Glc} p \mathrm{NAc}-(1 \rightarrow 4)-\beta$ Rhap-(1 $\rightarrow 4)-\beta-G l c p]$, but $24 \mathrm{~F}$ has arabinitol-1- $\mathrm{PO}_{4}$, and 24B has ribitol-1- $\mathrm{PO}_{4}$ attached to $\beta$-Rhap. Our structure of $24 \mathrm{~F}$ is identical to that described in a recent US patent application (34). In contrast to $24 \mathrm{~F}$ and $24 \mathrm{~B}, 24 \mathrm{~A}$ has a four-residue backbone that lacks

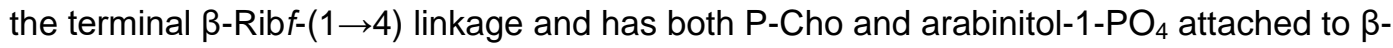
GlcpNAc and $\beta-$ Rhap, respectively. Serotype $24 \mathrm{C}$ has both $24 \mathrm{~F}$ and $24 \mathrm{~B}$ repeating units, and both repeating units are likely present in a single PS chain. However, the ratio of ribitol to arabinitol varies among different $24 \mathrm{C}$ isolates. This variation indicates the heterogeneity in the capsule structure, which may be culture media dependent and could lead to serotyping inconsistency. These structures provide insights into the serological profile associated with $24 \mathrm{C}, 24 \mathrm{~F}, 24 \mathrm{~B}$, and $24 \mathrm{~A}$. All serologic findings can be explained if 
FS24d recognizes arabinitol present in $24 \mathrm{~A}, 24 \mathrm{~F}$ and $24 \mathrm{C}$, and FS24e recognizes ribitol in 24B and 24C. It is also interesting to speculate if FS24C recognizes P-Cho.

It was arduous to identify the functional role of the cps genes of these capsule

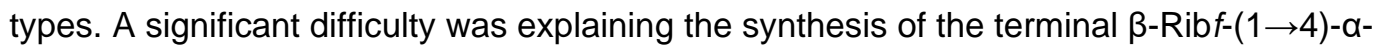

Rhap. An identical structure was found in 19B/19C and 7B/7C/7D capsules, and studies with $19 \mathrm{~B} / 19 \mathrm{C}$ concluded that $r b s F$ was responsible for the synthesis of NDP-ribose, a precursor of the Ribf and a hypothetical GT, $w c h R$, acted as Ribf transferase $(33,35)$. However, serotypes $24 \mathrm{~F}, 24 \mathrm{~B}$, and $24 \mathrm{C}$ cps loci have only rbs $F$ and lack a wchR equivalent. The same conundrum was also reported for serotypes 7B/7C/7D: they do not have $w c h R$ in their $c p s$ loci $(30,32)$. Perhaps $r b s F$ is bi-functional; i.e., it performs both biosynthetic as well as transferase activity and is sufficient by itself. Alternatively, another gene outside of the cps locus may perform the function of wchR. Another remote possibility is that $r b s F$ is only a Ribftransferase just like the wbs $Z$ gene found in the Oantigen type $\mathrm{O} 11$ of Shigella and that the NDP-ribose could be naturally available (36). For instance, ribose residues are mainly derived from fructose by the hexose-to-pentose conversion pathway in forming the T1 antigen of salmonella (37). Altogether, it seems that $r b s F$ alone is sufficient and that a $w c h R$-like gene may not be needed to catalyze the Ribf $(1 \rightarrow 4)$ linkage. We believe that 19B PS synthesis should be re-examined to better define the role of $w c h R$ in capsule synthesis.

Another difficulty arose from the genetic diversity of serotype 24B. Instead of arabinitol as is in $24 \mathrm{~F}, 24 \mathrm{~B}$ has ribitol, which is a stereoisomer of arabinitol and is structurally very similar. CDP-arabinitol and CDP-ribitol, the precursors for arabinitol and ribitol, respectively, are derived from a common intermediate of the pentose phosphate pathway, i.e., D-ribulose-5P $(31,38)$. Pneumococci constitutively produce CDP-ribitol for 
TA synthesis by the enzymes TarJ and Tarl (38). On the other hand, CDP-arabinitol in pneumococci is explicitly produced for capsule synthesis using three genes ( $r p E, a b p A$, and $a b p B$ ), with the $a b p A$ and $a b p B$ genes being found within the cps loci (31). It was presumed and confirmed that $w c x G$ is a bi-specific phosphotransferase enzyme capable of adding either arabinitol or ribitol. In addition, it was previously reported that serotype 24B has a frameshift mutation in $a b p A$, rendering its product nonfunctional (29). We have now shown that $24 \mathrm{~B}$ isolates have various mutations in the conserved motifs of $a b p A$, which are known to be critical in sugar-nucleoside diphosphate enzymes and in the binding of cofactor $F A D, N A D$, or $\mathrm{NAD}(\mathrm{P}) \mathrm{H}(31,39-41)$. Thus, serotype 24B does not have one single genetic basis. This knowledge should help genetic identification of serotype $24 B$ in the future.

Lastly, the genetic bases of $24 \mathrm{C}$ were also heterogeneous. However, all of them may reduce the availability of CDP-arabinitol and permit wcxG, a bi-specific phosphotransferase, to add both arabinitol and ribitol. Consistent with this possibility, 24C isolates showed mutations in $a b p A$ or $a b p B$. One strain has a longer open reading frame of $a b p A$, and the other has a shorter open reading frame. In the third strain, the $a b p B$ gene has a mutation. Also, these genetic heterogeneities are reflected in the observed variation in ribitol/arabinitol ratio. Further, in addition to CDP-arabinitol, the availability of CDP-ribitol may influence the structure as well. It is interesting to speculate if the serotype 24C capsule would contain less ribitol when CDP-ribitol is diverted more to TA synthesis $(38,42-44)$.

The genetic variability of serotypes $24 \mathrm{~B}$ and $24 \mathrm{C}$ is intriguing. One possibility is that serotype 24F strains colonize the nasopharynx (NP) and thereby circulate in the population, but that $24 \mathrm{~F}$ becomes (microevolves) into either $24 \mathrm{~B}$ or $24 \mathrm{C}$ in the course of 
invading body niches other than the NP (45). When 24F invades deeper tissues, it may encounter immune defense targeting the arabinitol and thus switch to $24 \mathrm{~B}$ or $24 \mathrm{C}$ to avoid the immune defense (46). Consistent with this hypothesis, most of our $24 \mathrm{C}$ isolates were recovered from IPD. An earlier study reported the simultaneous recovery of serotypes 24F and 24B from exudates of the middle ear or blood culture (47). Further, it would be interesting to investigate if $24 \mathrm{~B}$ is less common than $24 \mathrm{~F}$ among NP isolates of the pneumococcus and if $24 \mathrm{~B}$ is more common in IPD isolates.

The bi-specificity of wcxG also predicts that new serotypes may potentially be discovered. Serotypes $17 \mathrm{~F}$ and $24 \mathrm{~A}$ have $w c x G$, $a b p A$, and $a b p B$ and have arabinitol in their structure. If their arabinitol synthesis is reduced or blocked, the two strains should produce capsules using ribitol instead of arabinitol. Further, given that we were able to delete the wcxG gene experimentally, there may be serogroup 24 strains with inactive wcxG. As ribitol and arabinitol appear to be the epitopes of the factor sera $24 \mathrm{~d}$ and $24 \mathrm{e}$, the factor sera could be helpful in identifying potential serogroup 24 variants.

Subsequent to the introduction of PCV13 in many countries, it has been estimated that nearly half of childhood IPD cases (42.2\%) were due to NVTs (48). However regional differences were observed ranging from $9.2 \%$ in eastern Mediterranean region to $71.9 \%$ in Europe (48). On summarizing the serotype data from 29 European countries, the European Center for Disease Prevention and Control reported serotype 24F as the topranked NVT implicated in IPDs (10.1\%) in children $<5$ years old. $(15,49)$. Since 2012 , Japan $(19,20)$, Germany $(21,22)$, France $(23,24,50)$, UK $(25,26)$, Denmark $(27,28)$, and Israel (51) have seen an increasing incidence of serotype $24 \mathrm{~F}$ with a high invasive disease potential (52). In contrast, serotype $24 \mathrm{~F}$ has been an infrequent cause of IPD in USA $(17,18)$. Given the minor genetic differences between the $24 \mathrm{~F}, 24 \mathrm{~B}$, and $24 \mathrm{C}$ 
serotypes, it is possible that a $24 \mathrm{~F}$ strain may evolve into a $24 \mathrm{~B}$ or $24 \mathrm{C}$ strain. Our findings should facilitate monitoring the epidemiology of the emergent serogroup 24 subtypes and should eventually aid in the development of high-valency conjugate vaccines.

In the wake of conjugate vaccine usage, it is possible that the $24 \mathrm{C}$ serotype is more prevalent and is as widely distributed as $24 \mathrm{~F}$ or $24 \mathrm{~B}$. Consistent with this possibility, additional 24C isolates have been identified among clinical isolates in the UK, Germany, Italy, and Belgium (Table S2). Of note, 24C strains belong to diverse multilocus sequence types (MLST) (Table S3), which further underpins their widespread existence. Even though majority of the $24 \mathrm{C}$ isolates (13 out of 14 isolates) were recovered from invasive disease, we cannot ignore its presence in the NP at the present time $(53,54)$. Such strains need to be traced through the large carriage and IPD epidemiological studies. The capsule PS of $24 \mathrm{~F}$ may be included in future generations of PCVs $(34,55,56)$. Given its structural similarity and serological cross-reactivity, future vaccines containing $24 \mathrm{~F}$ would be cross-reactive with $24 \mathrm{~B}$ or $24 \mathrm{C}$. Serotype $24 \mathrm{C}$ may be a possible alternative for inclusion in PCVs since it expresses epitopes of both 24B and 24F.

\section{Methods}

\section{Bacterial strains and cultivation}

All bacterial strains examined in this study are listed in Table 1. Strains MNY585-

-MNY591 were collected between 2012 and 2017 as a part of IPD surveillance at the National Reference Center for Streptococci, Germany. Strain PHE194136 was collected in 2015 during routine IPD surveillance activities at Public Health England, UK. Pneumococcal strains SSISP24A, SSISP24B, and SSISP24F, representing serotypes 24A, 24B, and 24F, respectively, were from Statens Serum Institut (SSI), Copenhagen, 
Denmark; a serotype 24F strain (STREP24F) was from the Nahm laboratory bacterial strain collection (57).

All bacterial strains were cultured on blood agar plates supplemented with $5 \%$ sheep blood (Remel Laboratories, Lenexa, KS) and were incubated overnight at $37^{\circ} \mathrm{C}$ in $5 \% \mathrm{CO}_{2}$. Each pneumococcal strain was identified using standard microbiological tests, including colony morphology and optochin susceptibility $(9,58)$. Isolated colonies were inoculated into Todd-Hewitt broth with $5 \%$ yeast extract (THY) and grown to mid-log density (optical density at $600 \mathrm{~nm}\left[\mathrm{OD}_{600}\right]$ of 0.5 ), and the bacteria were frozen in THY with $15 \%$ glycerol at $-80^{\circ} \mathrm{C}$ for later use.

\section{Serological properties of serogroup 24 isolates}

Initially, all the German isolates were serotyped at the National Reference Center for Streptococci, Germany, using the classical Quellung reaction. The PHE194136 strain was serotyped at the Technical University of Denmark, also using the Quellung reaction. For genetic and structural characterization, the serological properties of all the isolates were re-assessed at the Nahm laboratory, University of Alabama at Birmingham, by the slide agglutination reaction, as previously described $(59,60)$, using polyclonal rabbit antisera obtained from the SSI Copenhagen, Denmark (Table 1). Briefly, a single isolated colony was inoculated in $10 \mathrm{~mL}$ of $\mathrm{THY}$ broth and grown in a $37^{\circ} \mathrm{C}$ water bath until the $\mathrm{OD}_{600}$ reached to 0.6. After incubation, the bacteria were centrifuged $(15,344 \times g, 10 \mathrm{~min})$, washed, and resuspended in $50 \mu \mathrm{L}$ of $0.9 \% \mathrm{NaCl}$. Two $\mu \mathrm{L}$ of bacterial suspension was added onto a glass slide and mixed with an equal amount of the pool or factor sera as detailed in Table 1. The mixture was then observed under the microscope for clumping or agglutination. 


\section{Capsule polysaccharide isolation, purification, and detection} Capsule polysaccharide was purified from MNY585, MNY586, and MNY589 (24X strains) as described previously (7). Briefly, a single colony of each pneumococcal strain was grown in 1 liter of a chemically defined medium (61), supplemented with choline chloride (1 g/liter), sodium bicarbonate (2.5 g/liter), and cysteine $\mathrm{HCl}$ ( $0.73 \mathrm{~g} /$ /iter). After overnight incubation, the bacteria were separated from the supernatant by centrifugation $(15,344 \times$ $g$; $\left.30 \mathrm{~min} ; 4^{\circ} \mathrm{C}\right)$; resuspended in $0.9 \% \mathrm{NaCl}$ with sodium deoxycholate $(0.05 \%)$, mutanolysin $(100 \mathrm{U} / \mathrm{mL})$, and lysozyme $(11.8 \mathrm{mg} / \mathrm{mL})$; and incubated at $37^{\circ} \mathrm{C}$ for $72 \mathrm{~h}$. The lysate was centrifuged, dialyzed, and subjected to anion-exchange chromatography. Fractions containing the PS were detected and quantified with an inhibition-type enzymelinked immunosorbent assay (ELISA) developed and performed as described previously (7). The ELISA plates were coated at $37^{\circ} \mathrm{C}$ with $5 \mu \mathrm{g} / \mathrm{mL}$ of $24 \mathrm{~F}$ capsular PS (SSI, Copenhagen, Denmark) for $5 \mathrm{~h}$ in phosphate-buffered saline. The samples containing PS were incubated $1: 1$ with pool $C$ antiserum at 1:24,000 dilutions. After washing, the bound antibodies were detected with alkaline phosphatase-conjugated goat anti-rabbit Ig (Southern Biotech) at 1:3,000 dilutions. After developing with paranitrophenyl phosphate substrate (Sigma) in diethanolamine buffer, the optical density at $405 \mathrm{~nm}\left(\mathrm{OD}_{405}\right)$ was recorded for each well. The fractions with a high polysaccharide concentration, low cell wall polysaccharide (CWPS) concentration, and low absorbance at 260 and $280 \mathrm{~nm}$ were pooled, dialyzed, and lyophilized. Purified 24F PS (SSI, Copenhagen, Denmark) was used as an assay standard.

Capsule polysaccharide from PHE194136 (24X strain), 24F/2 (24F strain), 24B/2 (24B strain), and 24A/2 (24A strain) was purified by lysing the serum bouillon grown cells with deoxycholate followed by sequential ethanol precipitation (25-80\%), as described 
previously $(35,62)$. The purified PS was sonicated in $\mathrm{D}_{2} \mathrm{O}$ using a Labsonic $\mathrm{P}$ ultrasonic homogenizer with a 3-mm probe (Sartorius, Germany) for $2 \mathrm{~h}$ under an ice bath, followed by desalting, concentration (Amicon Ultra- $10 \mathrm{kDa}$ ), and lyophilization.

\section{Nuclear magnetic resonance (NMR) spectroscopy}

NMR samples were prepared by dissolving $\sim 5 \mathrm{mg}$ of lyophilized PS in $0.5 \mathrm{~mL}$ of $99.99 \%$

$\mathrm{D}_{2} \mathrm{O}$ (Cambridge Isotope Laboratories) and transferred to 5- or 3-mm NMR tubes. All the one-dimensional (1D) and two-dimensional (2D) nuclear magnetic resonance (NMR) data $\left({ }^{1} \mathrm{H}-{ }^{1} \mathrm{H}\right.$ and $\left.{ }^{1} \mathrm{H}-{ }^{13} \mathrm{C}\right)$ were collected at $323 \mathrm{~K}$ on a Bruker Avance III $\left(799.90 \mathrm{MHz}\right.$ for ${ }^{1} \mathrm{H}$ and 201.14 MHz for $\left.{ }^{13} \mathrm{C}\right)$ equipped with a $5-\mathrm{mm} \mathrm{TCl}{ }^{1} \mathrm{H} /\left({ }^{13} \mathrm{C},{ }^{15} \mathrm{~N}\right)$ cryoprobe or a Bruker AVANCE 600-MHz instrument with a 5-mm SmartProbe $B B(F)-H-D\left({ }^{15} \mathrm{~N}-{ }^{31} \mathrm{P},{ }^{1} \mathrm{H},{ }^{19} \mathrm{~F}\right)(35$, $62)$.

The assignments of ${ }^{1} \mathrm{H}$ and ${ }^{13} \mathrm{C}$ signals were achieved by the following $2 \mathrm{D}$ experiments: double quantum filtered correlation spectroscopy $\left({ }^{1} \mathrm{H}-{ }^{1} \mathrm{H}\right.$ DQF-COSY), total correlation spectroscopy $\left({ }^{1} \mathrm{H}-{ }^{1} \mathrm{H}\right.$ TOCSY $)$ with a 80-ms mixing time, overhauser spectroscopy $\left({ }^{1} \mathrm{H}-{ }^{1} \mathrm{H}\right.$ NOESY) with a 150 - to 400 -ms mixing time, heteronuclear multiple quantum coherence $\left({ }^{1} \mathrm{H}-{ }^{13} \mathrm{C} \mathrm{HMQC}\right)$, heteronuclear multiple bond correlation $\left({ }^{1} \mathrm{H}-{ }^{13} \mathrm{C}\right.$ $\mathrm{HMBC}$ ) spectra optimized for 8-Hz long-range coupling constants. The $1 \mathrm{D}^{31} \mathrm{P}$ NMR spectra were recorded by 256 scans with sweep widths of $12175.324 \mathrm{~Hz}$. The ${ }^{1} \mathrm{H}^{-}{ }^{31} \mathrm{P}$ HMBC was optimized for 8-Hz coupling constants with 4096x256 points. NMR spectra were processed on Topspin 4.07 (Bruker) using zero filling to 2 times the data size in the direct dimension and 4 times the data size in the indirect dimension. The one-dimensional ${ }^{1} \mathrm{H}$ spectra were processed with an exponential window function with a line broadening of $0.3 \mathrm{~Hz}$ for ${ }^{1} \mathrm{H}$ spectra. The $2 \mathrm{D}$ spectra were processed with shifted sine bell window 
functions in both dimensions. Residual cell wall polysaccharide phosphocholine signals

$\left({ }^{1} \mathrm{H} 3.2 \mathrm{ppm}\right.$ and ${ }^{13} \mathrm{C} 54.5 \mathrm{ppm}$ and the shielded ${ }^{31} \mathrm{P}$ signal at $\left.1.6075 \mathrm{ppm}\right)$ were used as a reference. The ratio of arabinitol to ribitol was determined based on the integrals of the HSQC peak (Ara-ol-2:Rib-ol-2).

\section{Whole-genome sequencing and phylogenetic analysis}

Whole-genome sequencing (WGS) was done by the Institute for Food \& Health Core Facility Microbiome/NGS at the Technical University of Munich. DNA libraries for WGS were constructed by the Nextera XT DNA sample prep kit (Illumina, San Diego, CA, USA) and then sequenced using the MiSeq platform (Illumina). The resulting paired-end sequencing reads were analyzed using the program FastQC (v0.11.3) and quality trimmed using Trimmomatic (63). The genomes were assembled de novo with SPADES (v3.11.1) (64) to obtain draft whole-genome assembly (contigs), and the quality of the assembly was verified using QUAST (v4.6.3) (65). The unordered contigs were ordered against the reference genome of D39 (GenBank accession no. CP000410.2) using Mauve (Version snapshot 2015-02-13 build 0). The cps locus from each draft genome was extracted and aligned with the reference cps loci retrieved from NCBI (http://www.ncbi.nlm.nih.gov/) viz., cps24F (CR931688), cps24B (CR931687), and cps24A (CR931686). The cps loci were annotated by using the GenBank annotation and Prokka (v1.12) (66). Further analysis of the extracted cps loci was done using the CLC Main Workbench 8 (Qiagen, Hilden, Germany) and the Geneious prime v2019.2 (Biomatters).

To predict the biosynthetic roles of the $w c x l$ and $w c x J$ cps genes, phylogenetic analysis was performed with the homologs from other serotypes viz., 2, 7F, 10A, 15A, 
17A, 17F, 18F, 19F, 23F, 27, 35B, and 45. The gene names and GenBank accession numbers are provided in the supplemental material (Fig. S4). Phylogenetic analyses were conducted based on genetic distance using the Geneious prime v2019.2 (Biomatters). Full-length amino acid sequences were aligned using MUSCLE, and trees were constructed based on the neighbor-joining method using the Tamura-Nei model with 1,000 bootstrap replicates. The phylogenetic tree (Newick format) was visualized and edited in the online tool Interactive Tree of Life.

\section{Genetic manipulations}

Isogenic strains were constructed using the TIGR-JS strain (unencapsulated TIGR4 strain) containing a Janus cassette $(67,68)$. The cell lysates (cps loci donor) of $24 \mathrm{C}$ strains (MNY585 and MNY586), 24F strain (MNY576), 24B strain (MNY583), and 24A strain (MNY580) were mixed with the TIGR-JS cells for transformation in competence medium (Todd-Hewitt broth plus $0.5 \%$ yeast extract, $0.2 \%$ bovine serum albumin, $0.01 \%$ calcium chloride, and competence stimulating peptide 1 at $50 \mathrm{ng} / \mathrm{\mu L}$ ), as described previously (8). Transformants were then selected on Todd-Hewitt broth plus $0.5 \%$ yeast extract (THY) agar plates containing 100-300 $\mu \mathrm{g} / \mathrm{mL}$ streptomycin and were backcrossed 3 times with TIGR-JS.

Mutant strains FG205, FG206, and FG207 were constructed by deleting the wcxG, $w c x K_{s}$, and $w z y_{s}$ genes, respectively, from FG204 (Isogenic $24 \mathrm{C}$ strain derived from MNY586) through allelic exchange with the Sweet Janus cassette with selection for kanamycin resistance and streptomycin and sucrose susceptibility (69). For gene deletion, upstream and downstream flanking regions were amplified from FG204, and the Sweet Janus cassette was amplified from YNL001 (wciZ defective 15B strain, derived 
from BLS141 by replacing the wciZ gene with the Sweet Janus cassette (70)). The three individual fragments were assembled into a single construct by overlap extension PCR

(71). The purified PCR product was transformed into FG204 for recombination as described above. Transformants were then selected on THY agar plates containing 150 $\mu \mathrm{g} / \mathrm{mL}$ of kanamycin. Primer sets used for the genetic manipulation are presented in Table S1.

The uptake of the cps loci and PCR constructs was confirmed by Sanger sequencing from purified chromosomal DNA, which was performed by the Heflin Center Genomics Core Lab at the University of Alabama at Birmingham (UAB). The isogenic strains and mutant strains were tested for serological properties using Quellung and slide agglutination reactions with serogroup 24 reagents as described in Table 3.

\section{GenBank accession numbers}

Sequences for the complete cps locus from 24C strains (MNY585-MNY591), 24F strains (MNY576-MNY578), 24B strains (MNY582-MNY584), and 24A strains (MNY579-MNY581) were uploaded to GenBank and assigned accession numbers MW683289-MW683304. Similarly, the Sanger sequences of a $\sim 2.6 \mathrm{~kb}$ region (wcxG, $a b p A$ and $a b p B$ genes) of the $24 \mathrm{C}$ strains (MNY585, MNY586, and MNY589), 24F strain (MNY576), 24B strain (MNY583), and 24A strain (MNY580) were uploaded to GenBank and assigned accession numbers MW447149- MW447154.

\section{Acknowledgments}

This work was supported with funding from the National Institutes of Health (AG-050607) to M.H.N. The High-Field NMR facility at the University of Alabama at Birmingham (UAB) was established through the NIH (1S10RR026478) and is currently supported by the 
Comprehensive Cancer Center (NCI grant P30 CA013148). The 800-MHz NMR spectra were recorded at the NMR Center in the Technical University of Denmark (DTU), supported by the Villum Foundation. C.L. appreciates the financial support of the China

Scholarship Council (PhD scholarship No. 201708310119). We acknowledge Dr.

Katarzyna Duda (Research Center Borstel) for chemical compositional analyses.

\section{Competing interests}

UAB has Intellectual Property Rights on some reagents used in the study. FG and MHN are UAB employees. The authors declare that they have no other relevant conflicts of interest.

\section{References}

1. Cooper CA, Mainprize IL, Nickerson NN. 2015. Genetic, biochemical, and structural analyses of bacterial surface polysaccharides. Adv Exp Med Biol 883:295-315.

2. Mostowy RJ, Holt KE. 2018. Diversity-Generating Machines: Genetics of bacterial sugar-coating. Trends Microbiol 26:1008-1021.

3. Siber GR, Thompson C, Reid GR, Almeido-Hill J, Zacher B, Wolff M, Santosham M. 1992. Evaluation of bacterial polysaccharide immune globulin for the treatment or prevention of Haemophilus influenzae type $b$ and pneumococcal disease. $J$ Infect Dis 165 Suppl 1:S129-33.

4. Andrews NJ, Waight PA, Burbidge P, Pearce E, Roalfe L, Zancolli M, Slack M, Ladhani SN, Miller E, Goldblatt D. 2014. Serotype-specific effectiveness and correlates of protection for the 13-valent pneumococcal conjugate vaccine: A postlicensure indirect cohort study. Lancet Infect Dis 14:839-46. 
5. Croucher NJ, Harris SR, Fraser C, Quail MA, Burton J, van der Linden M, McGee L, von Gottberg A, Song JH, Ko KS, Pichon B, Baker S, Parry CM, Lambertsen

LM, Shahinas D, Pillai DR, Mitchell TJ, Dougan G, Tomasz A, Klugman KP, Parkhill J, Hanage WP, Bentley SD. 2011. Rapid pneumococcal evolution in response to clinical interventions. Science 331:430-4.

6. Geno KA, Gilbert GL, Song JY, Skovsted IC, Klugman KP, Jones C, Konradsen HB, Nahm MH. 2015. Pneumococcal capsules and their types: Past, present, and future. Clin Microbiol Rev 28:871-99.

7. Ganaie F, Saad JS, McGee L, van Tonder AJ, Bentley SD, Lo SW, Gladstone RA, Turner P, Keenan JD, Breiman RF, Nahm MH. 2020. A new pneumococcal capsule type, 10D, is the 100th serotype and has a large cps fragment from an oral streptococcus. mBio 11.

8. Nahm MH, Brissac T, Kilian M, Vlach J, Orihuela CJ, Saad JS, Ganaie F. 2020. Pneumococci can become virulent by acquiring a new capsule from oral streptococci. J Infect Dis 222:372-380.

9. Song JY, Eun BW, Nahm MH. 2013. Diagnosis of pneumococcal pneumonia: current pitfalls and the way forward. Infect Chemother 45:351-66.

10. LaFon DC, Nahm MH. 2018. Measuring immune responses to pneumococcal vaccines. J Immunol Methods 461:37-43.

11. Naucler P, Galanis I, Morfeldt E, Darenberg J, Ortqvist A, Henriques-Normark B. 2017. Comparison of the impact of pneumococcal conjugate vaccine 10 or pneumococcal conjugate vaccine 13 on invasive pneumococcal disease in equivalent populations. Clin Infect Dis 65:1780-1789. 
12. Hausdorff WP, Hanage WP. 2016. Interim results of an ecological experiment Conjugate vaccination against the pneumococcus and serotype replacement. Hum Vaccin Immunother 12:358-74.

13. Hulten KG. 2018. The changing epidemiology of pneumococcal diseases. Lancet Infect Dis 18:929-930.

14. Tin Tin Htar M, Christopoulou D, Schmitt HJ. 2015. Pneumococcal serotype evolution in Western Europe. BMC Infect Dis 15:419.

15. Levy C, Ouldali N, Caeymaex L, Angoulvant F, Varon E, Cohen R. 2019. Diversity of serotype replacement after pneumococcal conjugate vaccine implementation in Europe. J Pediatr 213:252-253 e3.

16. Lochen A, Croucher NJ, Anderson RM. 2020. Divergent serotype replacement trends and increasing diversity in pneumococcal disease in high income settings reduce the benefit of expanding vaccine valency. Sci Rep 10:18977.

17. Beall B, Chochua S, Gertz RE, Jr., Li Y, Li Z, McGee L, Metcalf BJ, Ricaldi J, Tran T, Walker H, Pilishvili T. 2018. A population-based descriptive atlas of invasive pneumococcal strains recovered within the U.S. During 2015-2016. Front Microbiol 9:2670.

18. Varghese J, Chochua S, Tran T, Walker H, Li Z, Snippes Vagnone PM, Lynfield R, McGee L, Li Y, Metcalf BJ, Pilishvili T, Beall B. 2020. Multistate population and whole genome sequence-based strain surveillance of invasive pneumococci recovered in the USA during 2017. Clin Microbiol Infect 26:512 e1-512 e10.

19. Nakano S, Fujisawa T, Ito Y, Chang B, Suga S, Noguchi T, Yamamoto M, Matsumura Y, Nagao M, Takakura S, Ohnishi M, Ihara T, Ichiyama S. 2016. Serotypes, antimicrobial susceptibility, and molecular epidemiology of invasive and 
non-invasive Streptococcus pneumoniae isolates in paediatric patients after the introduction of 13-valent conjugate vaccine in a nationwide surveillance study conducted in Japan in 2012-2014. Vaccine 34:67-76.

20. Chiba N, Morozumi M, Shouji M, Wajima T, Iwata S, Ubukata K, Invasive Pneumococcal Diseases Surveillance Study G. 2014. Changes in capsule and drug resistance of pneumococci after introduction of PCV7, Japan, 2010-2013. Emerg Infect Dis 20:1132-9.

21. Weinberger R, von Kries R, van der Linden M, Rieck T, Siedler A, Falkenhorst G. 2018. Invasive pneumococcal disease in children under 16years of age: Incomplete rebound in incidence after the maximum effect of PCV13 in 2012/13 in Germany. Vaccine 36:572-577.

22. van der Linden M, Falkenhorst G, Perniciaro S, Imohl M. 2015. Effects of infant pneumococcal conjugate vaccination on serotype distribution in invasive pneumococcal disease among children and adults in Germany. PLoS One 10:e0131494.

23. Ouldali N, Varon E, Levy C, Angoulvant F, Georges S, Ploy MC, Kempf M, Cremniter J, Cohen R, Bruhl DL, Danis K. 2021. Invasive pneumococcal disease incidence in children and adults in France during the pneumococcal conjugate vaccine era: An interrupted time-series analysis of data from a 17-year national prospective surveillance study. Lancet Infect Dis 21:137-147.

24. Alari A, Chaussade H, Domenech De Celles M, Le Fouler L, Varon E, Opatowski L, Guillemot D, Watier L. 2016. Impact of pneumococcal conjugate vaccines on pneumococcal meningitis cases in France between 2001 and 2014: A time series analysis. BMC Med 14:211. 
25. Kandasamy R, Voysey M, Collins S, Berbers G, Robinson H, Noel I, Hughes H, Ndimah S, Gould K, Fry N, Sheppard C, Ladhani S, Snape MD, Hinds J, Pollard AJ. 2020. Persistent circulation of vaccine serotypes and serotype replacement after 5 years of infant immunization with 13-valent pneumococcal conjugate vaccine in the United Kingdom. J Infect Dis 221:1361-1370.

26. Waight PA, Andrews NJ, Ladhani NJ, Sheppard CL, Slack MP, Miller E. 2015. Effect of the 13-valent pneumococcal conjugate vaccine on invasive pneumococcal disease in England and Wales 4 years after its introduction: An observational cohort study. Lancet Infect Dis 15:629.

27. Kavalari ID, Fuursted K, Krogfelt KA, Slotved HC. 2019. Molecular characterization and epidemiology of Streptococcus pneumoniae serotype 24F in Denmark. Sci Rep 9:5481.

28. Slotved HC, Dalby T, Hoffmann S. 2016. The effect of pneumococcal conjugate vaccines on the incidence of invasive pneumococcal disease caused by ten nonvaccine serotypes in Denmark. Vaccine 34:769-74.

29. Mavroidi A, Aanensen DM, Godoy D, Skovsted IC, Kaltoft MS, Reeves PR, Bentley SD, Spratt BG. 2007. Genetic relatedness of the Streptococcus pneumoniae capsular biosynthetic loci. J Bacteriol 189:7841-55.

30. Bentley SD, Aanensen DM, Mavroidi A, Saunders D, Rabbinowitsch E, Collins M, Donohoe K, Harris D, Murphy L, Quail MA, Samuel G, Skovsted IC, Kaltoft MS, Barrell B, Reeves PR, Parkhill J, Spratt BG. 2006. Genetic analysis of the capsular biosynthetic locus from all 90 pneumococcal serotypes. PLoS Genet 2:e31. 
31. Wang Q, Xu Y, Perepelov AV, Knirel YA, Reeves PR, Shashkov AS, Guo X, Ding P, Feng L. 2012. Biochemical characterization of the CDP-D-arabinitol biosynthetic pathway in Streptococcus pneumoniae 17F. J Bacteriol 194:1868-74.

32. Aanensen DM, Mavroidi A, Bentley SD, Reeves PR, Spratt BG. 2007. Predicted functions and linkage specificities of the products of the Streptococcus pneumoniae capsular biosynthetic loci. J Bacteriol 189:7856-76.

33. Morona JK, Morona R, Paton JC. 1999. Comparative genetics of capsular polysaccharide biosynthesis in Streptococcus pneumoniae types belonging to serogroup 19. J Bacteriol 181:5355-64.

34. Porambo, RJ, Abeygunawardana C, Musey LK, Kosinski MJ, Cui YA, Mchugh P, Konietzko J. 2019. Pneumococcal polysaccharides and their use in immunogenic polysaccharide-carrier protein conjugates. US patent [US20210038723A1].

35. Kjeldsen C, Slott S, Elverdal PL, Sheppard CL, Kapatai G, Fry NK, Skovsted IC, Duus JØ. 2018. Discovery and description of a new serogroup 7 Streptococcus pneumoniae serotype, 7D, and structural analysis of 7C and 7D. Carbohydr Res 463:24-31.

36. Tao J, Feng L, Guo H, Li Y, Wang L. 2004. The O-antigen gene cluster of Shigella boydii $\mathrm{O} 11$ and functional identification of its wzy gene. FEMS Microbiol Lett 234:125-32.

37. Sarvas M, Nikaido H. 1971. Biosynthesis of T1 antigen in Salmonella: Origin of Dgalactofuranose and D-ribofuranose residues. J Bacteriol 105:1063-72.

38. Baur S, Marles-Wright J, Buckenmaier S, Lewis RJ, Vollmer W. 2009. Synthesis of CDP-activated ribitol for teichoic acid precursors in Streptococcus pneumoniae. J Bacteriol 191:1200-10. 
39. Breton C, Oriol R, Imberty A. 1998. Conserved structural features in eukaryotic and prokaryotic fucosyltransferases. Glycobiology 8:87-94.

40. Brockhausen I. 2014. Crossroads between bacterial and mammalian glycosyltransferases. Front Immunol 5:492.

41. Kleiger G, Eisenberg D. 2002. GXXXG and GXXXA motifs stabilize FAD and $\mathrm{NAD}(\mathrm{P})$-binding Rossmann folds through $\mathrm{C}($ alpha) $-\mathrm{H} \ldots$.. O hydrogen bonds and van der waals interactions. J Mol Biol 323:69-76.

42. Lee CJ, Fraser BA, Boykins RA, Li JP. 1987. Effect of culture conditions on the structure of Streptococcus pneumoniae type 19A(57) capsular polysaccharide. Infect Immun 55:1819-23.

43. Troxler LJ, Werren JP, Schaffner TO, Mostacci N, Vermathen P, Vermathen M, Wuthrich D, Simillion C, Brugger SD, Bruggmann R, Hathaway LJ, Furrer J, Hilty M. 2019. Carbon source regulates polysaccharide capsule biosynthesis in Streptococcus pneumoniae. J Biol Chem 294:17224-17238.

44. McFadden DC, Fries BC, Wang F, Casadevall A. 2007. Capsule structural heterogeneity and antigenic variation in Cryptococcus neoformans. Eukaryot Cell $6: 1464-73$

45. Calix JJ, Dagan R, Pelton SI, Porat N, Nahm MH. 2012. Differential occurrence of Streptococcus pneumoniae serotype $11 \mathrm{E}$ between asymptomatic carriage and invasive pneumococcal disease isolates reflects a unique model of pathogen microevolution. Clin Infect Dis 54:794-9.

46. Geno KA, Spencer BL, Bae S, Nahm MH. 2018. Ficolin-2 binds to serotype 35B pneumococcus as it does to serotypes $11 \mathrm{~A}$ and 31 , and these serotypes cause more infections in older adults than in children. PLoS One 13:e0209657. 
47. Venkateswaran PS, Stanton N, Austrian R. 1983. Type variation of strains of Streptococcus pneumoniae in capsular serogroup 15. J Infect Dis 147:1041-1054.

48. Balsells E, Guillot L, Nair H, Kyaw MH. 2017. Serotype distribution of Streptococcus pneumoniae causing invasive disease in children in the post-PCV era: A systematic review and meta-analysis. PLoS One 12:e0177113.

49. Control ECfDPa. 2017. Invasive pneumococcal disease - Annual epidemiological report for 2017. Solna, Sweden: ECDC; 2017.

50. Levy C, Varon E, Ouldali N, Bechet S, Bonacorsi S, Cohen R. 2020. Changes in invasive pneumococcal disease spectrum after 13-valent pneumococcal conjugate vaccine implementation. Clin Infect Dis 70:446-454.

51. Ben-Shimol S, Givon-Lavi N, Grisaru-Soen G, Megged O, Greenberg D, Dagan R, Israel B, Meningitis Active Surveillance G. 2018. Comparative incidence dynamics and serotypes of meningitis, bacteremic pneumonia and other-IPD in young children in the PCV era: Insights from Israeli surveillance studies. Vaccine 36:5477-5484.

52. Varon E, Cohen R, Bechet S, Doit C, Levy C. 2015. Invasive disease potential of pneumococci before and after the 13-valent pneumococcal conjugate vaccine implementation in children. Vaccine 33:6178-85.

53. Camilli R, Daprai L, Cavrini F, Lombardo D, D'Ambrosio F, Del Grosso M, Vescio MF, Landini MP, Pascucci MG, Torresani E, Garlaschi ML, Sambri V, Pantosti A. 2013. Pneumococcal carriage in young children one year after introduction of the 13-valent conjugate vaccine in Italy. PLoS One 8:e76309.

54. Alfayate Miguelez S, Yague Guirao G, Menasalvas Ruiz AI, Sanchez-Solis M, Domenech Lucas M, Gonzalez Camacho F, Ortiz Romero MM, Espejo Garcia P, 
Guerrero Gomez C, lofrio de Arce A, Moreno Parrado L, Sanchez Andrada RM, Cascales Alcolea E, Lorente Garcia S, Paredes Reyes P, Casquet Barcelo A,

Lopez Yepes ML, Vigueras Abellan JJ, Sanz Mateo G, Murcian Pneumococcal

Study G. 2020. Impact of pneumococcal vaccination in the nasopharyngeal carriage of Streptococcus pneumoniae in healthy children of the Murcia region in Spain. Vaccines (Basel) 9.

55. Klugman KP, Rodgers GL. 2021. Time for a third-generation pneumococcal conjugate vaccine. Lancet Infect Dis 21:14-16.

56. Cohen R, Levy C, Ouldali N, Goldrey M, Bechet S, Bonacorsi S, Varon E. 2020. Invasive disease potential of pneumococcal serotypes in children after PCV13 implementation. Clin Infect Dis doi:10.1093/cid/ciaa917.

57. Burton RL, Nahm MH. 2006. Development and validation of a fourfold multiplexed opsonization assay (MOPA4) for pneumococcal antibodies. Clin Vaccine Immunol 13:1004-9.

58. Govindan V, Ganaie F, Nagaraj G, Hussain A, K L RK. 2016. Laboratory based identification of pneumococcal infections: Current and future. Pediatr Infect Dis 8:76-78.

59. Calix JJ, Oliver MB, Sherwood LK, Beall BW, Hollingshead SK, Nahm MH. 2011. Streptococcus pneumoniae serotype $9 \mathrm{~A}$ isolates contain diverse mutations to wcjE that result in variable expression of serotype 9V-specific epitope. J Infect Dis 204:1585-95.

60. Henrichsen J. 1995. Six newly recognized types of Streptococcus pneumoniae. J Clin Microbiol 33:2759-2762. 
61. van de Rijn I, Kessler RE. 1980. Growth characteristics of group A streptococci in a new chemically defined medium. Infect Immun 27:444-8.

62. Li C, Duda KA, Elverdal PL, Skovsted IC, Kjeldsen C, Duus JO. 2019. Structural, biosynthetic, and serological cross-reactive elucidation of capsular polysaccharides from Streptococcus pneumoniae Serogroup 16. J Bacteriol 201.

63. Bolger AM, Lohse M, Usadel B. 2014. Trimmomatic: a flexible trimmer for Illumina sequence data. Bioinformatics 30:2114-20.

64. Bankevich A, Nurk S, Antipov D, Gurevich AA, Dvorkin M, Kulikov AS, Lesin VM, Nikolenko SI, Pham S, Prjibelski AD, Pyshkin AV, Sirotkin AV, Vyahhi N, Tesler G, Alekseyev MA, Pevzner PA. 2012. SPAdes: A new genome assembly algorithm and its applications to single-cell sequencing. J Comput Biol 19:455-77.

65. Mikheenko A, Prjibelski A, Saveliev V, Antipov D, Gurevich A. 2018. Versatile genome assembly evaluation with QUAST-LG. Bioinformatics 34:i142-i150.

66. Seemann T. 2014. Prokka: Rapid prokaryotic genome annotation. Bioinformatics 30:2068-9.

67. Park IH, Park S, Hollingshead SK, Nahm MH. 2007. Genetic basis for the new pneumococcal serotype, 6C. Infect Immun 75:4482-9.

68. Sung CK, Li H, Claverys JP, Morrison DA. 2001. An rpsL cassette, Janus, for gene replacement through negative selection in Streptococcus pneumoniae. Appl Environ Microbiol 67:5190-5196.

69. Li Y, Thompson CM, Lipsitch M. 2014. A modified Janus cassette (Sweet Janus) to improve allelic replacement efficiency by high-stringency negative selection in Streptococcus pneumoniae. PLoS One 9:e100510. 
759

760

761

762

763

764

765

766

767

768

769

770

771

772

773

774

775

776

777

778

779

780

781

782

70. Spencer BL, Shenoy AT, Orihuela CJ, Nahm MH. 2017. The pneumococcal serotype $15 \mathrm{C}$ capsule is partially O-acetylated and allows for limited evasion of 23 valent pneumococcal polysaccharide vaccine-elicited anti-serotype 15B antibodies. Clin Vaccine Immunol 24:e00099-17.

71. Lee J, Lee HJ, Shin MK, Ryu WS. 2004. Versatile PCR-mediated insertion or deletion mutagenesis. Biotechniques 36:398-400. 
Table 1. Serologic profiles of all serogroup 24 strains used in this study

\begin{tabular}{ccccccccc}
\hline Strain name & Alias & Serotype & Origin & $\begin{array}{c}\text { Year of } \\
\text { isolation }\end{array}$ & & \multicolumn{5}{c}{ Antisera } \\
\cline { 6 - 9 } & & & & Pool C & FS24c & FS24d & FS24e \\
\hline SSISP24A & - & $24 \mathrm{~A}$ & n/a & n/a & + & + & + & - \\
24A/2 & - & $24 \mathrm{~A}$ & Denmark & 1940 & + & + & + & - \\
MNY579 & BAN43 & $24 \mathrm{~A}$ & Germany & 2002 & + & + & + & - \\
MNY580 & KON145 & $24 \mathrm{~A}$ & Germany & 2011 & + & + & + & - \\
MNY581 & PS20506 & $24 \mathrm{~A}$ & Germany & 2013 & + & + & + & - \\
SSISP24F & - & $24 \mathrm{~F}$ & n/a & $\mathrm{n} / \mathrm{a}$ & + & - & + & - \\
24F/2 & - & $24 \mathrm{~F}$ & USA & 1940 & + & - & + & - \\
STREP24F & - & $24 \mathrm{~F}$ & USA & 2016 & + & - & + & - \\
MNY576 & PS35887 & $24 \mathrm{~F}$ & Germany & 2018 & + & - & + & - \\
MNY577 & PS35852 & $24 \mathrm{~F}$ & Germany & 2018 & + & - & + & - \\
MNY578 & RKI5893 & $24 \mathrm{~F}$ & Germany & 2018 & + & - & + & - \\
SSISP24B & - & $24 \mathrm{~B}$ & n/a & n/a & + & - & - & + \\
24B/2 & - & $24 \mathrm{~B}$ & Denmark & 1942 & + & - & - & + \\
MNY582 & WYCA2012A & $24 \mathrm{~B}$ & Germany & 2014 & + & - & - & + \\
MNY583 & PS14342 & $24 \mathrm{~B}$ & Germany & 2010 & + & - & - & + \\
MNY584 & RKI5781 & $24 \mathrm{~B}$ & Germany & 2017 & + & - & - & + \\
MNY585 & RKI4410 & $24 \mathrm{X}$ & Germany & 2012 & + & - & + & + \\
MNY586 & RK14707 & $24 \mathrm{X}$ & Germany & 2014 & + & - & + & + \\
MNY587 & PS20830 & $24 \mathrm{X}$ & Germany & 2013 & + & - & + & + \\
MNY588 & PS20629 & $24 \mathrm{X}$ & Germany & 2013 & + & - & + & + \\
MNY589 & PS20848 & $24 \mathrm{X}$ & Germany & 2013 & + & - & + & + \\
MNY590 & RKI4697 & $24 \mathrm{X}$ & Germany & 2014 & + & - & + & + \\
MNY591 & PS31906 & $24 \mathrm{X}$ & Germany & 2017 & + & - & + & + \\
PHE194136 & - & $24 \mathrm{X}$ & England & 2015 & + & - & + & + \\
\hline
\end{tabular}

784

Pneumococcal strains SSISP24A, SSISP24F, and SSISP24B are from Statens Serum Institut (SSI). Pool C and factor antisera (FS24c, FS24d, and FS24e) are also from SSI.

"24X" strains reacted with both FS24d and FS24e. STREP24F is a multiplex

opsonophagocytic assay (MOPA) target strain from Nahm laboratory bacterial strain collection. Negative reactions (-) and positive reactions (+) are shown. For the serologic studies, isolates were grown in Todd-Hewitt broth w/0.5\% yeast extract (THY) broth. n/a, information not available. 
Table 2. Chemical shift assignments of serotype $24 \mathrm{C}, 24 \mathrm{~F}, 24 \mathrm{~B}$, and $24 \mathrm{~A}$ repeating units

\begin{tabular}{|c|c|c|c|c|c|c|c|c|c|c|}
\hline \multirow[b]{2}{*}{ Serotype } & \multirow[b]{2}{*}{ Residue } & \multirow[b]{2}{*}{ Label } & \multicolumn{8}{|c|}{ NMR chemical shift (proton/carbon shift) (ppm) } \\
\hline & & & H1/C1 & $\mathrm{H} 2 / \mathrm{C2}$ & H3/C3 & $\mathrm{H} 4 / \mathrm{C} 4$ & $\mathrm{H} 5 / \mathrm{C} 5$ & H6/C6 & NAc & $\mathrm{PO}_{4}$ \\
\hline \multirow{7}{*}{$24 \mathrm{C}$} & $\beta$-Ribf & A & $5.296 / 108.57$ & $4.025 / 75.49$ & $4.089 / 71.39$ & $3.992 / 83.00$ & $3.781,3.659 / 63.58$ & & & \\
\hline & a-Rhap & B & $4.913 / 100.77$ & $3.740 / 71.45$ & $3.885 / 70.92$ & $3.482 / 79.13$ & $4.342 / 67.40$ & $1.237 / 17.50$ & & \\
\hline & $\beta$-GlcpNAc & $\mathrm{C}$ & $4.882 / 100.30$ & $3.863 / 56.20$ & $3.807 / 77.20$ & $3.861 / 73.69$ & $3.535 / 75.61$ & ND/ ND & $2.06 / 22.83$ & \\
\hline & $\beta$-Rhap & $\mathrm{D}$ & $4.776 / 100.71$ & $4.232 / 70.45$ & $4.204 / 78.25$ & $3.731 / 76.67$ & $3.440 / 70.74$ & $1.327 / 17.67$ & & \\
\hline & $\beta-G \mid c p$ & $\mathrm{E}$ & $4.472 / 101.53$ & $3.200 / 73.79$ & $3.609 / 75.85$ & $3.279 / 79.31$ & $3.480 / 75.49$ & $4.038,3.658 / 62.36$ & & \\
\hline & Arabinitol & $\mathrm{F} 1$ & $4.003,3.975 / 67.28$ & $4.067 / 69.51$ & $3.631 / 70.86$ & $3.757 / 71.51$ & $3.819,3.655 / 63.42$ & & & -0.274 \\
\hline & Ribitol & $\mathrm{F} 2$ & $4.121,4.022 / 67.04$ & $3.940 / 71.51$ & $3.735 / 72.21$ & $3.847 / 72.62$ & $3.799,3.653 / 62.88$ & & & -0.041 \\
\hline \multirow{5}{*}{$24 \mathrm{~F}$} & a-Rhap & B & $4.916 / 100.70$ & $3.744 / 71.47$ & $3.879 / 70.92$ & $3.483 / 79.24$ & $4.328 / 67.40$ & $1.236 / 17.56$ & & \\
\hline & $\beta$-GlcpNAc & C & $4.885 / 100.35$ & $3.859 / 56.26$ & $3.800 / 77.25$ & $3.857 / 73.85$ & $3.531 / 75.61$ & ND/ND & $2.063 / 22.84$ & \\
\hline & $\beta$-Rhap & D & $4.779 / 100.70$ & $4.231 / 70.45$ & $4.207 / 78.31$ & $3.727 / 76.66$ & $3.434 / 70.80$ & $1.326 / 17.68$ & & \\
\hline & $\beta-G \mid c p$ & $E$ & $4.469 / 101.52$ & $3.192 / 73.85$ & $3.613 / 75.96$ & $3.291 / 79.24$ & $3.478 / 75.49$ & $3.661,4.022 / 62.36$ & & \\
\hline & Arabinitol & $\mathrm{F}$ & $4.009,3.978 / 67.28$ & $4.064 / 69.63$ & $3.632 / 70.92$ & $3.760 / 71.62$ & $3.819,3.659 / 63.41$ & & & -0.276 \\
\hline \multirow{4}{*}{ 24B } & $\beta$-Ribf & A & $5.295 / 108.56$ & $4.030 / 75.49$ & $4.087 / 71.39$ & $3.997 / 83.11$ & $3.779,3.663 / 63.65$ & & & \\
\hline & a-Rhap & B & $4.915 / 100.70$ & $3.744 / 71.49$ & $3.885 / 70.92$ & $3.482 / 79.24$ & $4.327 / 67.40$ & $1.237 / 17.56$ & & \\
\hline & $\beta$-GlcpNAc & C & $4.886 / 100.35$ & $3.865 / 56.26$ & $3.799 / 77.25$ & $3.858 / 73.85$ & $3.533 / 75.61$ & ND/ ND & $2.062 / 22.84$ & \\
\hline & Ribitol & $\mathrm{F}$ & $4.127,4.025 / 67.05$ & $3.944 / 71.62$ & $3.737 / 72.33$ & $3.852 / 72.68$ & $3.803,3.660 / 62.94$ & & & -0.045 \\
\hline \multirow{5}{*}{$24 \mathrm{~A}$} & $\alpha-R h a p$ & A & $4.919 / 101.31$ & $3.750 / 71.00$ & $3.720 / 70.47$ & $3.366 / 72.23$ & $4.347 / 68.94$ & $1.204 / 17.10$ & & \\
\hline & $\beta$-GlcpNAc & B & $4.873 / 100.49$ & $3.873 / 55.93$ & $3.787 / 78.45$ & $3.914 / 73.28$ & $3.657 / 74.10$ & ND/ ND & $2.075 / 22.87$ & -0.471 \\
\hline & $\beta$-Rhap & C & $4.797 / 100.49$ & $4.215 / 70.12$ & $4.203 / 78.09$ & $3.697 / 76.92$ & $3.406 / 70.70$ & $1.292 / 17.57$ & & \\
\hline & $\beta$-Glcp & $\mathrm{D}$ & $4.557 / 101.43$ & $3.188 / 73.99$ & $3.645 / 75.63$ & $3.501 / 77.39$ & $3.459 / 75.16$ & $3.792,3.920 / 61.55$ & & \\
\hline & Arabinitol & $E$ & $3.976 / 67.07$ & $4.061 / 69.41$ & $3.612 / 70.70$ & $3.745 / 71.29$ & 3.804,3.819/63.31 & & & -0.305 \\
\hline
\end{tabular}

793 Each carbohydrate residue is labeled with a unique letter for 24C (A-F2), 24F (A-F), 24B (A-F), and 24A (A-E). Proton and

794 carbon are indicated by letters $\mathrm{H}$ and $\mathrm{C}$, respectively, and the numbers associated with them indicate their respective

795 chemical shift values. A slash separates the proton and carbon chemical shifts (ppm). For each residue, the table shows the 
796 chemical shifts of every proton and carbon molecule attached to it at different positions. $\mathrm{N}$-Ac, $\mathrm{N}$-acetylation. $\mathrm{PO}_{4}$,

797 phosphate. ND, not determined.

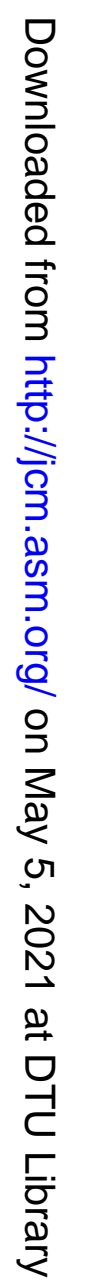


Table 3. Serological profile of capsule isogenic and mutant strains of serotype $24 \mathrm{C}$

\begin{tabular}{|c|c|c|c|c|c|}
\hline $\begin{array}{l}\text { Strain } \\
\text { name }\end{array}$ & Description & Pool C & FS24c & $\begin{array}{c}\text { FS24d } \\
\text { (Arabinitol) }\end{array}$ & $\begin{array}{l}\text { FS24e } \\
\text { (Ribitol) }\end{array}$ \\
\hline MNY576 & Serotype 24F & + & - & + & - \\
\hline MNY583 & Serotype 24B & + & - & - & + \\
\hline MNY579 & Serotype 24A & + & + & + & - \\
\hline MNY585 & Serotype $24 C$ & + & - & + & + \\
\hline MNY586 & Serotype $24 C$ & + & - & + & + \\
\hline FG104 & MNY576 cps + TIGR-JS & + & - & + & - \\
\hline FG604 & MNY583 cps + TIGR-JS & + & - & - & + \\
\hline FG504 & MNY579 cps + TIGR-JS & + & + & + & - \\
\hline FG701 & MNY585 cps + TIGR-JS & + & - & + & + \\
\hline FG204 & MNY586 cps + TIGR-JS & + & - & + & + \\
\hline FG205 & $\Delta w c x G \_24 C c p s$ & + & - & - & - \\
\hline FG206 & $\Delta w c x K_{s}^{-} 24 \mathrm{C} c p s$ & + & - & + & + \\
\hline FG207 & $\Delta w z y_{s} 24 C c p s$ & + & - & + & + \\
\hline TIGR-JS & unencapsulated & _ & - & - & - \\
\hline
\end{tabular}

799

800

801

MNY576, MNY583, MNY585, MNY586, and MNY579 are wild-type pneumococcal strains. FG104, FG604, FG701, and FG204 are capsule isogenic strains created by transferring the cps loci from the wild-type pneumococcal strain to the TIGR-JS genetic background as described in this table. FG205, FG206, and FG207 are mutant strains created by deleting the indicated cps gene (i.e. $w c x G$, $w c x K_{s}$, and $w z y_{s}$ ) from FG204 (derived from MNY586). TIGR-JS is an unencapsulated TIGR4 (serotype 4) pneumococcal strain. All pool and factor-specific antisera are from SSI. Negative reactions (-) and positive reactions (+) are shown. For the serologic studies, isolates were grown in Todd-Hewitt broth w/0.5\% yeast extract (THY) broth. 
Fig. 1. (A) Diagrammatic representation of the capsular biosynthetic (cps) loci of serotypes 24X (MNY586), 24F (CR931688 and MNY576), 24B (CR931687 and MNY583), and 24A (CR931686). The direction of the arrows indicates the transcriptional orientation. The symbol "Ø" designates a pseudogene, and tnp denotes transposase. The five-digit numbers at the $3^{\prime}$ end indicate the size (in bp) of the cps loci. CR931686-88 represents the GenBank accession no. of published cps sequences of serotype 24A, 24B, and 24F, respectively. The cps loci from representative German strains (MNY586, MNY576, and MNY583) are shown for comparison. Since the cps locus of the German 24A strains is similar to the published sequence, only the cps locus of CR931686 is shown. The previously known abp1 and abp2 genes were renamed as $a b p A$ and $a b p B$, respectively. (B) Multiple amino acid alignment of the abpA encoded proteins from multiple strains representing serotypes 24X, 24F, 24B, and 24A. CR931686, CR931687, and CR931688 are the GenBank accession numbers of the previously published sequences. MNY labeled sequences are from German strains. The serotype of the strain/sequence is provided in parenthesis next to the strain name/GenBank accession number. In the multiple alignment, the consensus amino acids are represented by dots. Amino acid differences are shown by one letter symbols. The complete consensus amino acid sequence is shown at the top of the multiple alignment. The numbers on top of the consensus amino acid sequence indicate the position of an amino acid. An asterisk represents a stop codon. GGxxG and DxD conserved motifs are boxed. Multiple amino acid alignment was performed by Multiple Alignment using Fast Fourier Transform (MAFFT) with scoring matrix $200 \mathrm{PAM} / \mathrm{K}=2$ and a gap open penalty of 1.5 . 
Fig. 2. (A) Selected region (3.60-4.00 ppm) of the ${ }^{1} \mathrm{H}-\mathrm{NMR}$ spectra shows the difference

837

838

839

840

841

842

843

844

845

846

847

848

849

850

851

852

853

854

855

856

857 56 57 in the structure of $24 \mathrm{~F}, 24 \mathrm{~B}$, and $24 \mathrm{C}$ capsule polysaccharides. STREP24F represents serotype $24 \mathrm{~F}$ and is from Nahm laboratory bacterial strain collection. SSISP24B represents serotype 24B and is from Statens Serum Institut (SSI). MNY585, MNY586, and MNY589 represent serotype $24 \mathrm{C}$, and the strains originated from Germany. Similarly, PHE194136 represents serotype 24C, and the strain originated from the UK. The selected region shows the mixture of side-chain peaks corresponding to ribitol and arabinitol in serotype $24 \mathrm{C}$. The peak at $3.735 \mathrm{ppm}$ corresponds to Tris. The spectra were obtained by the Carr-Purcell-Meiboom-Gill sequence (CPMG) method. (B) ${ }^{1} \mathrm{H}$ NMR spectra (chemical shifts 1.0-5.5 ppm). The spectra show that serotype 24A has a different PS structure from serotypes 24F, 24B, and 24C. The peak at $5.3 \mathrm{ppm}$, which corresponds to Ribf, is absent in SSISP24A (serotype 24A) and is shown in a black dotted box. SSISP24A represents serotype 24A and was obtained from Statens Serum Institut (SSI). A peak at $3.3 \mathrm{ppm}$ corresponds to phosphocholine (P-Cho), and a peak at $2.1 \mathrm{ppm}$ corresponds to dimethyl sulfoxide (DMSO). Asterisks denote impurities from cell wall polysaccharide. (1) 
Fig. 3. (A) Selected region (3.6-4.2 ppm) of HSQC spectra of $24 \mathrm{C}$ (Black) and 24F (Red) capsule polysaccharides showing superimposed (red and black) arabinitol (Ara-ol) and unique (black only) ribitol (Rib-ol) peaks. (B) Selected region (3.6-4.2 ppm) of HSQC spectra of 24C (black) and 24B (pink) capsule polysaccharides showing superimposed (pink and black) ribitol (Rib-ol) and unique (black only) arabinitol (Ara-ol) peaks. (C) 1D ${ }^{31} \mathrm{P}$ spectra of the ribitol and arabinitol phosphate regions in $24 \mathrm{C}$ capsule polysaccharide. The spectra show two phosphate $\left(\mathrm{PO}_{4}\right)$ groups in the $24 \mathrm{C}$ polysaccharide, one each linked to arabinitol and ribitol. Asterisks denote impurities from cell wall polysaccharide. In the peak labels, the letter indicates the sugar residue and the number denotes the carbon position (Table 2). Ribitol (Rib-ol) is labeled F1, and arabinitol (Ara-ol) is labeled F2 in Table 2. The $24 \mathrm{C}, 24 \mathrm{~F}$, and $24 \mathrm{~B}$ capsule polysaccharides shown in the figure were purified from PHE194136, 24F/2, and 24B/2 strains, respectively.

Fig. 4. Structures of the serogroup 24 (serotypes 24A, 24F, 24B, and 24C) capsule polysaccharides. The structure of the repeating unit of the capsule polysaccharide from each serotype is shown along with the cps genes (shown in red) responsible for the biosynthesis of the corresponding linkages. The structure of $24 \mathrm{C}$ capsule polysaccharide shows the mixture of $24 \mathrm{~F}$ and $24 \mathrm{~B}$ repeat units; however, the ratio (i.e., ribitol to arabinitol) is strain-dependent and may vary. The structural similarity between serotype $24 \mathrm{C}$ and serotypes $24 \mathrm{~F}, 24 \mathrm{~B}$, and $24 \mathrm{~A}$ explains the serological cross-reactivity with FS24d (recognizes arabinitol in serotypes 24F and 24A) and FS24e (recognizes ribitol in serotype 24B). 
Fig. 5. (A) Genetic manipulation diagram of $24 \mathrm{C}$ cps loci to study the function of the $w c x G, w c x K_{s}$ and $w z y_{s}$ genes. The FG204 strain was created by transferring the complete cps locus from MNY586 (serotype 24C) to an unencapsulated TIGR4 genetic background (TIGR4-JS). Mutant strains (FG205, FG206, and FG207) were derived from FG204 by deleting the $w c x G, w c x K_{s}$, and $w z y_{s}$ genes, respectively. The Sweet Janus cassette composed of $s a c B^{S}, K a n^{R}, r p s L^{S}$ was used for gene deletion. (B) Biochemical characterization of the effect of the wcxG gene in serotype 24C. The superimposed HSQC spectra (chemical shifts 3.6-4.2 ppm) of FG205 capsule polysaccharide (blue peaks) and MNY586 capsule polysaccharide (red peaks) show arabinitol (Ara-ol) and ribitol (Rib-ol) specific peaks in MNY586 but not in FG205 (red peaks without accompanying blue peaks). In the peak labels, the letter indicates the sugar residue, and the number denotes the carbon position (Table 2). Ribitol (Rib-ol) is labeled F1, and arabinitol (Ara-ol) is labeled F2 in chemical shift table (Table 2). Asterisks denote impurities from cell wall polysaccharide. The \# symbol denotes newly generated unknown peaks in FG205, which possibly are cell wall contaminants. 


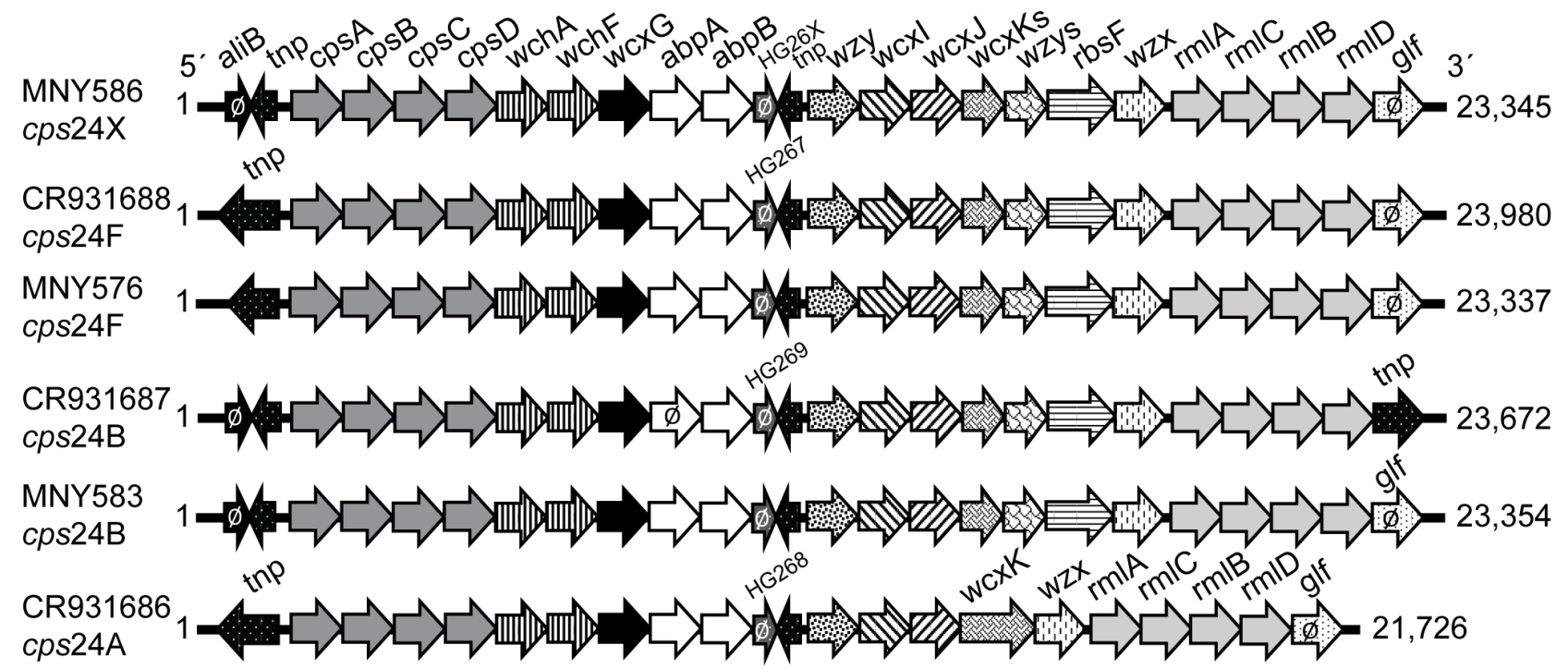

B

Consensus MNY585 (24X) MNY586 (24X) MNY589 (24X) MNY576 (24F) CR931688 (24F) MNY582 (24B) MNY583 (24B) CR931687 (24B) MNY580 (24A) CR931686 (24A)

Consensus MNY585 (24X) MNY586 (24X) MNY589 (24X) MNY576 (24F)

CR931688 (24F) MNY582 (24B) MNY583 (24B)

CR931687 (24B) MNY580 (24A) CR931686 (24A)

Consensus MNY585 (24X)

MNY586 (24X) MNY589 (24X) MNY576 (24F) CR931688 (24F) MNY582 (24B MNY583 (24B) CR931687 (24B) MNY580 (24A) CR931686 (24A)

Consensus MNY585 (24X) MNY586 (24X MNY589 (24X)

MNY576 (24F)

CR931688 (24F) MNY582 (24B)

MNY583 (24B)

MNY580 (24A) CR931686 (24A)

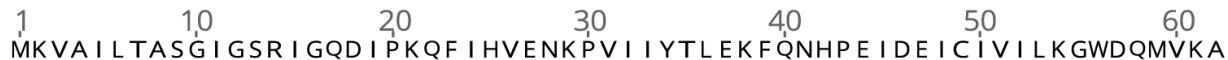
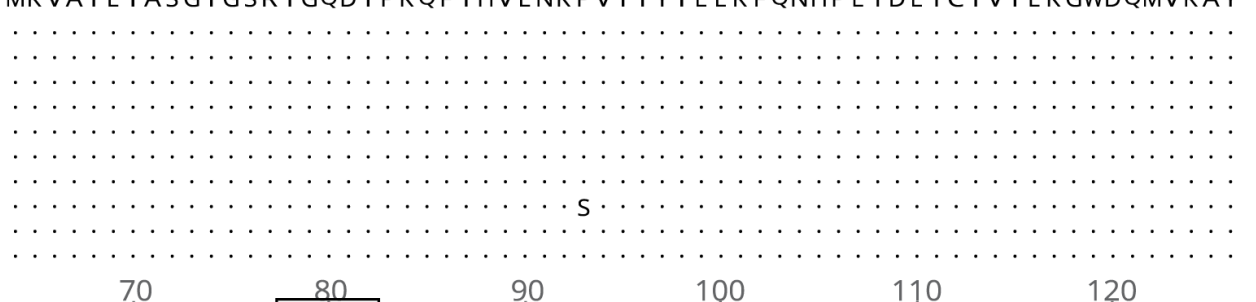

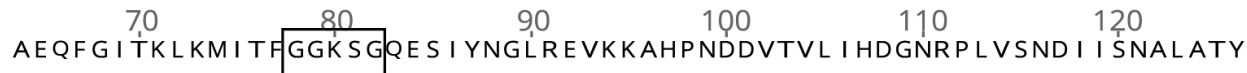

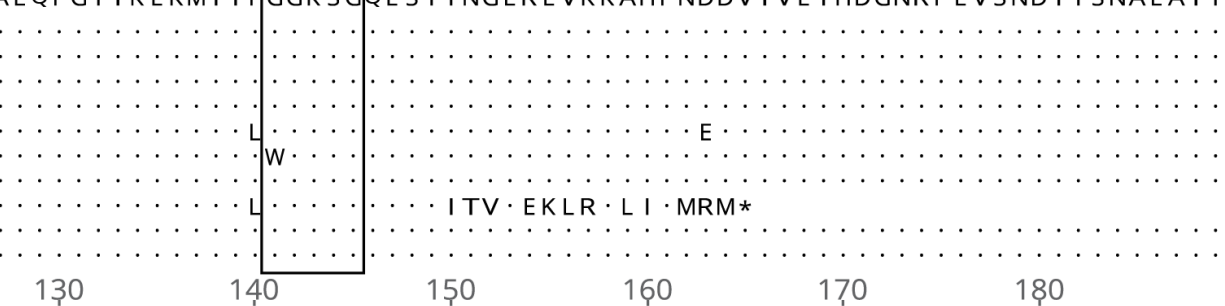

QQF GNAVAA I PTTÉVVFVL ENPQSTS STEALNRDL LRRTQTPHVYHLDN I LSLHEKALENG IT -

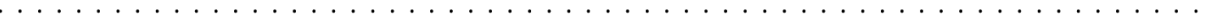

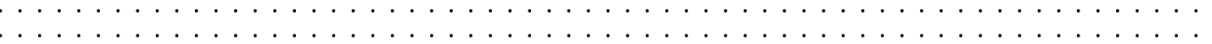
(190

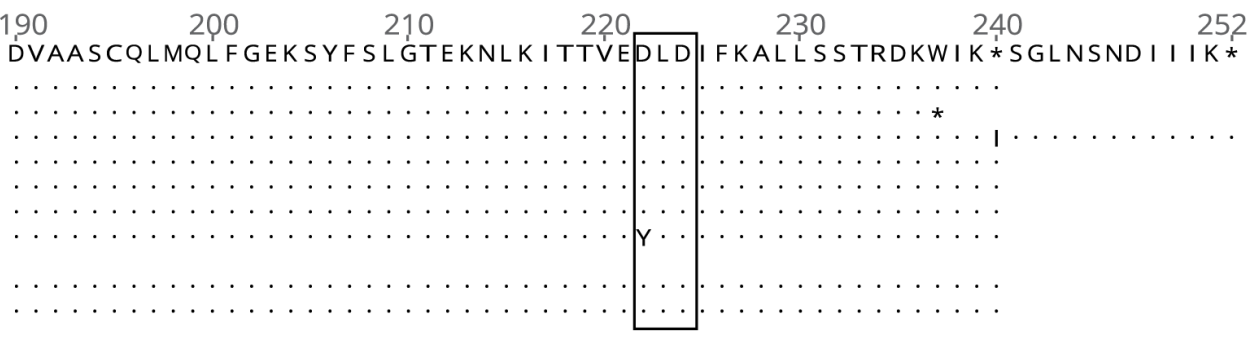




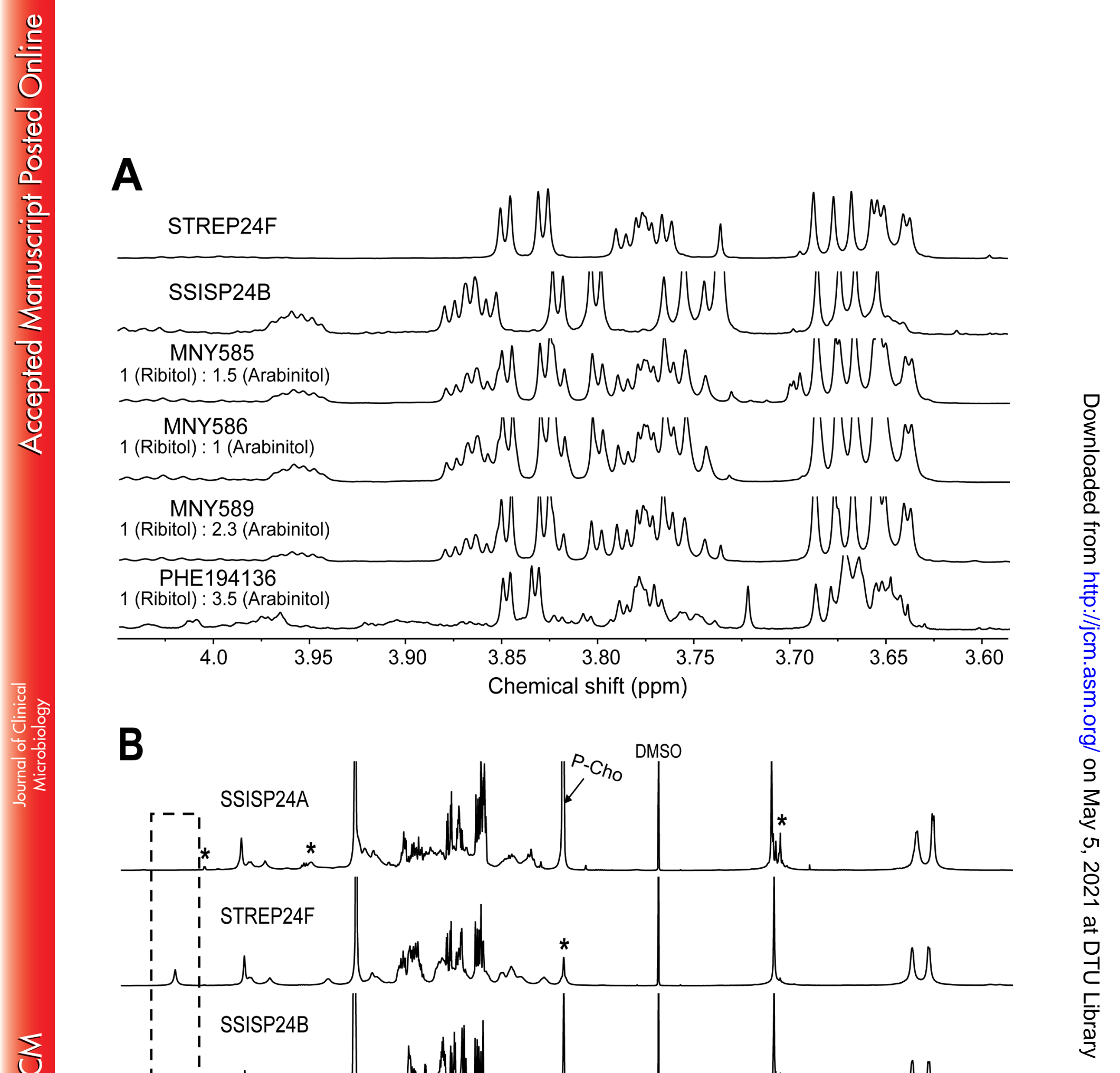




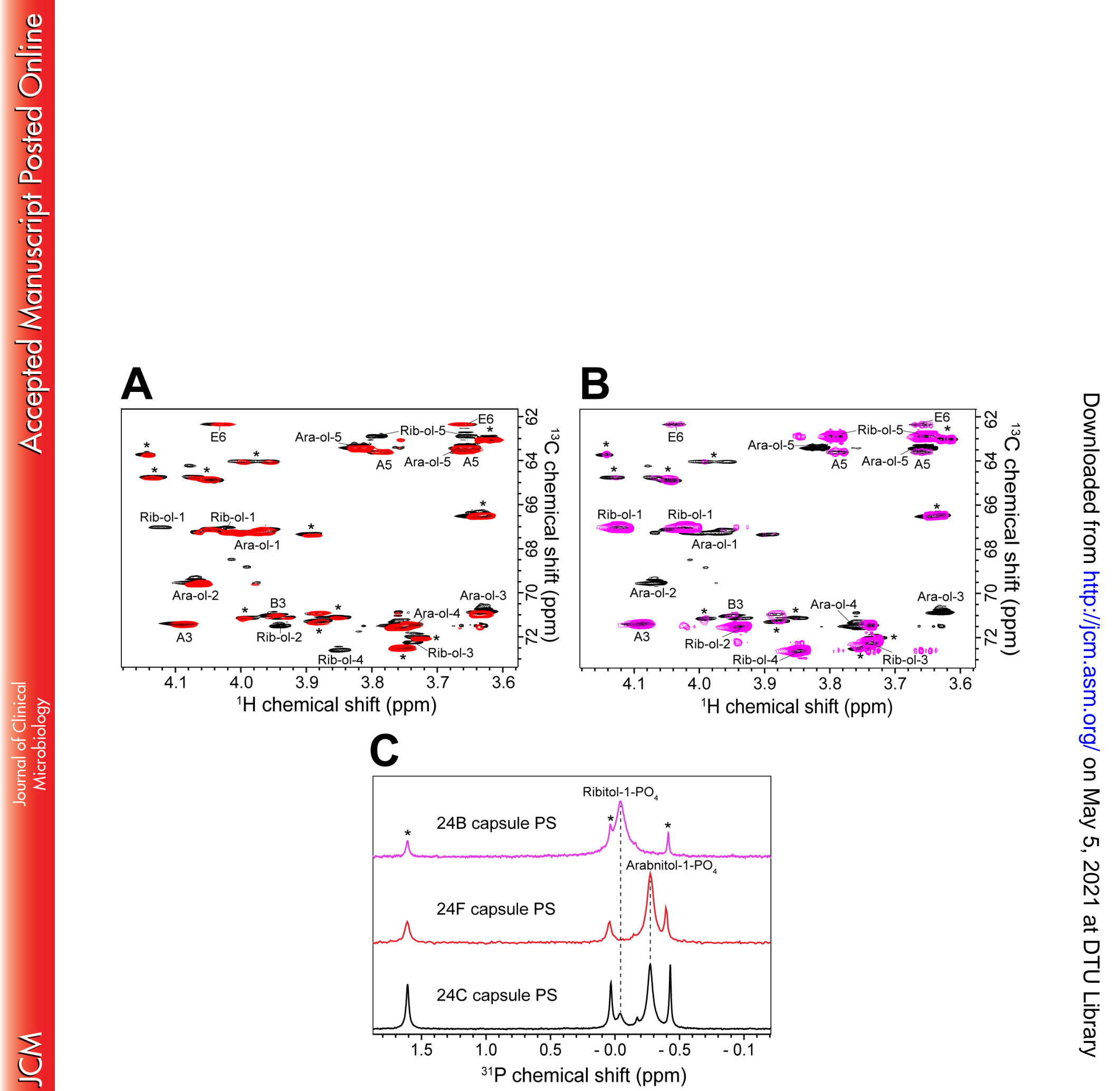



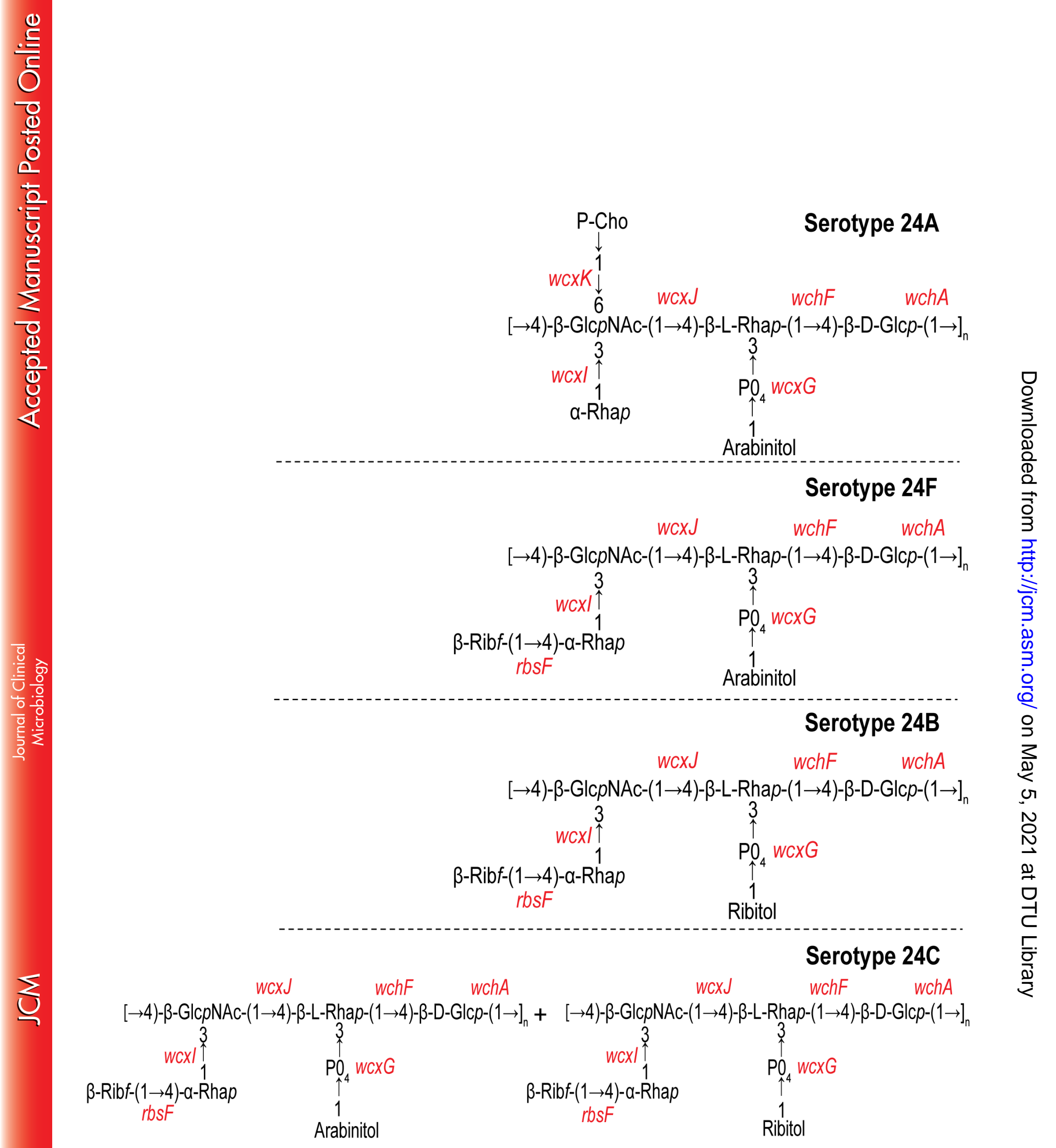
$\Delta$

MNY586

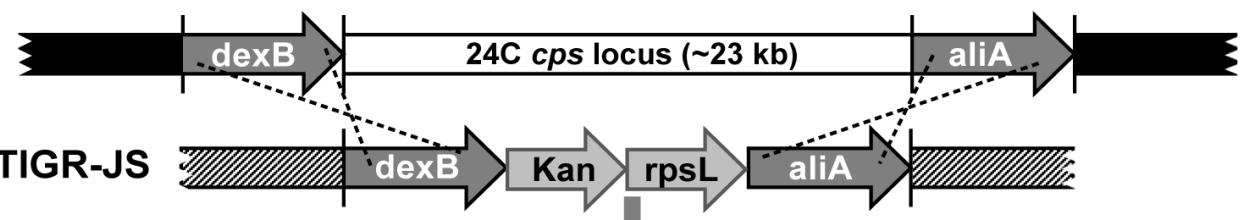

FG204
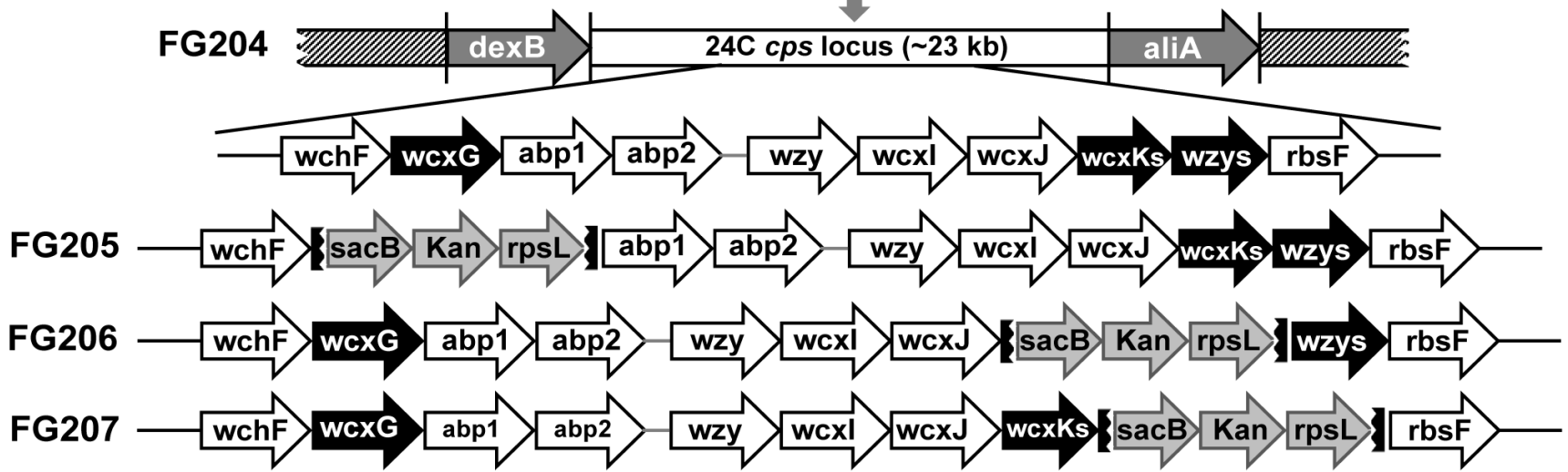

B

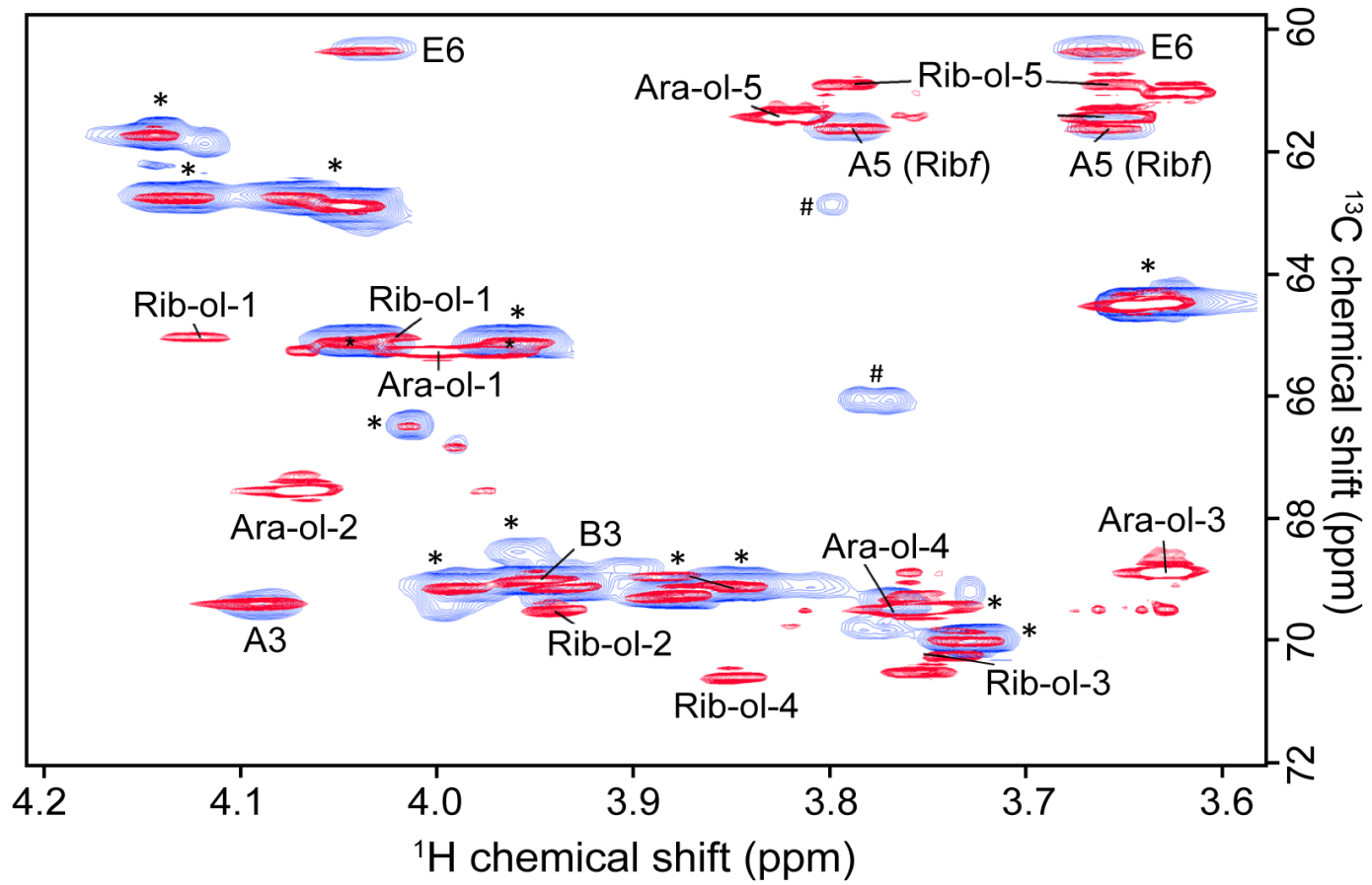

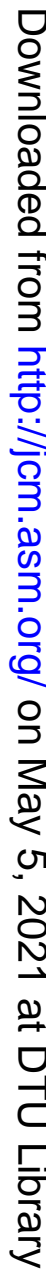

